Aalto University

School of Science

Degree Programme in Industrial Engineering and Management

Arjo Laukia

How does who we are affect where we go? Multiple identities and organizational outcomes

Master's Thesis

Espoo, May 23, 2012

Supervisor: $\quad$ Professor Juha-Antti Lamberg

Instructor: $\quad$ Professor Juha-Antti Lamberg 


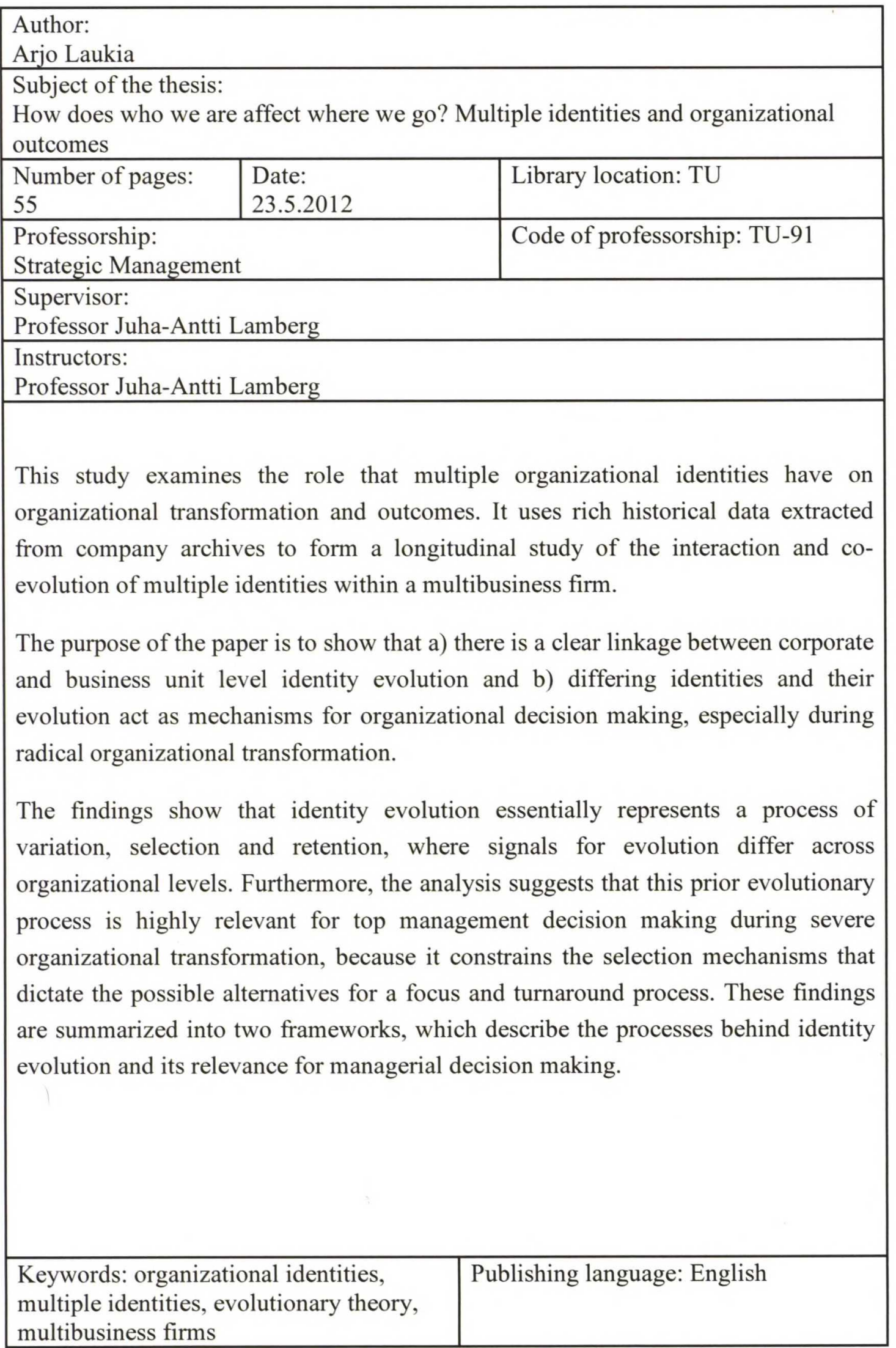




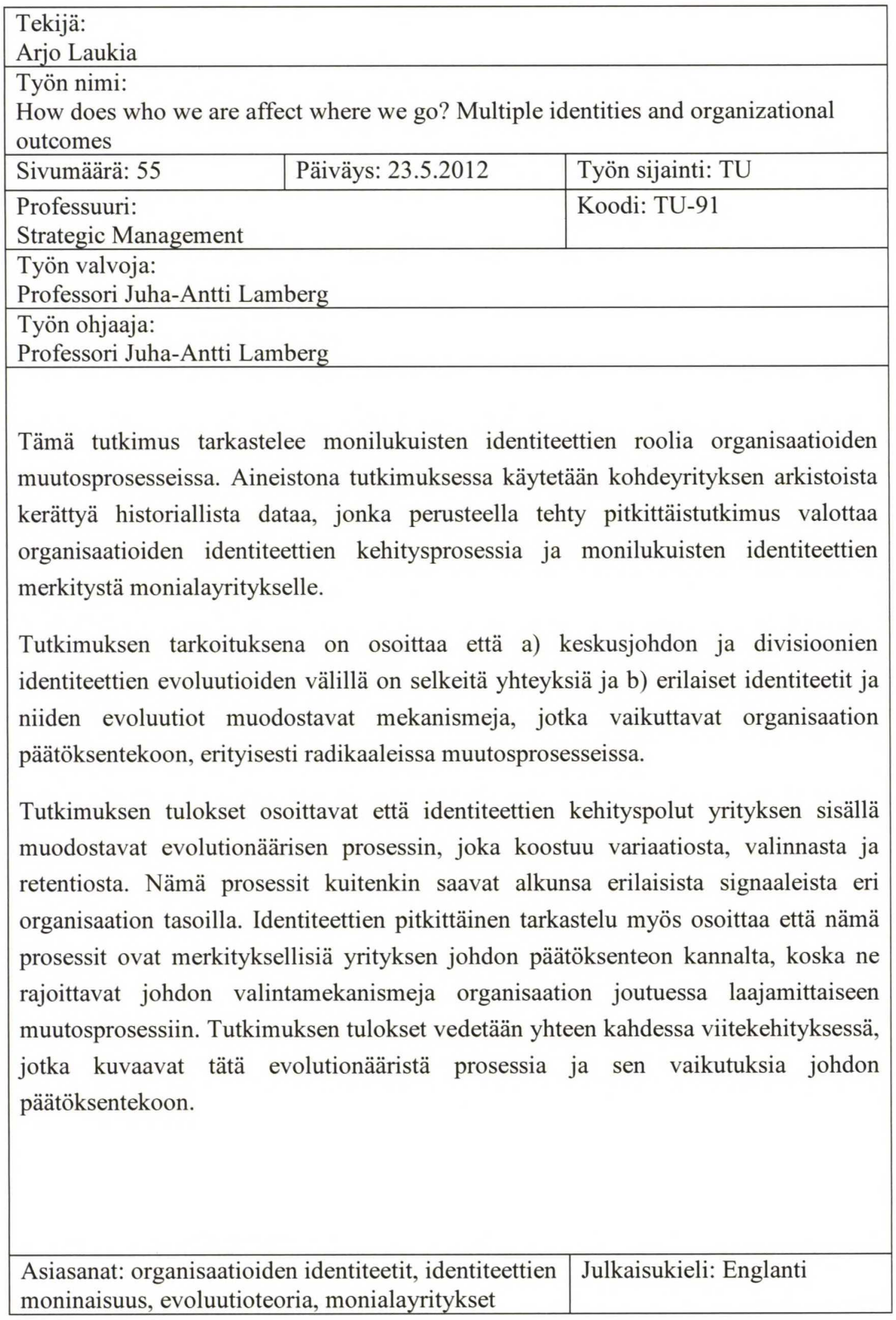




\section{Foreword and Acknowledgements}

This is it. The culmination point of all the hard work and wonderful experiences that have constituted my studies. The journey has been well worth it, but reaching the final checkpoint feels wonderful. This thesis is one of the results of a long process, which began several years ago with a summer job as a research assistant. That first taste of the academic realm was followed by an increasing interest in organizational research and the subsequent summers spent gathering data, sitting in dusty archives and writing articles has finally led me here. True to my prior academic work, this thesis has been written in article format. As such, it will hopefully find itself another home in the not too distant future in one of the journals of the field.

First and foremost, I am grateful for all of the support and guidance of Professor JuhaAntti Lamberg throughout my academic exploits. It has been an honor and a privilege to be able to work with one of the leading strategy researchers in the field. The extensive responsibilities and freedom granted by him from the very beginning of my academic "career" sparked my interest in the field and has kept the flame burning ever since.

I also need to thank several other academic instances, who have been very helpful throughout the process of writing this thesis. Specifically, I would like to thank the members of the GloStra (Global Strategy) research group, personnel of the Department of Industrial Engineering and Management as well as co-workers at the Institute of Strategy for insightful comments at conferences and informal gatherings. I would also 
like to extend my gratitude to Nokia and the Central Archives for Finnish Business Records (ELKA) for the unique opportunity of accessing their archives for data gathering.

Getting this far would not have been possible without the wonderful student community at Aalto University. Student life has formed a much needed counterbalance to all of the hard work and long nights studying. Thanks go especially to my guild Prodeko and the wonderful ProH08, the ever forward looking AYY and its board of 2011, FTMK08 and FTMK09 where I found countless new friends, and the boys of 7 whose humor and camaraderie are unmatched. The past six years have been the best of my life thanks to you.

I would also like to thank my parents and brothers for their continuous and unwavering support through life. My dear family has been a constant source of joy and happiness that has always spurred me onwards.

Last, but certainly not least, I would like to thank Vilma for being by my side. Without her insightfulness, challenging but constructive questioning and sunny disposition to life I would not be where I am academically or in life in general.

In Espoo, May 2012

Arjo Laukia 


\section{Contents}

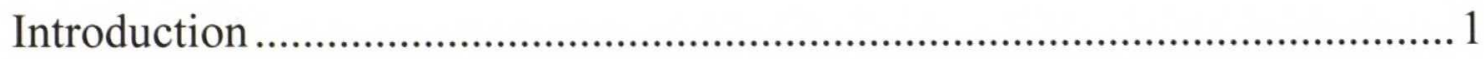

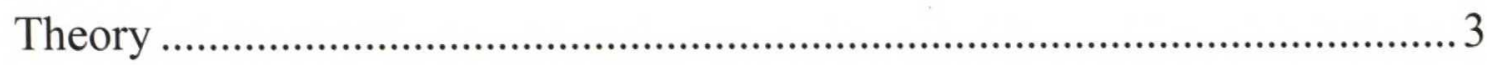

Organizational Identity ………………………………………………………. 3

Organizational Evolution .................................................................................. 7

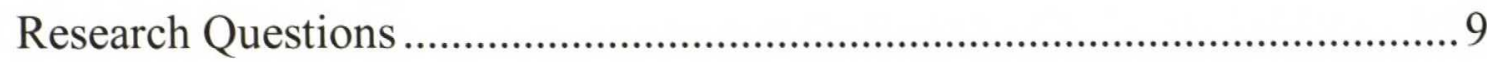

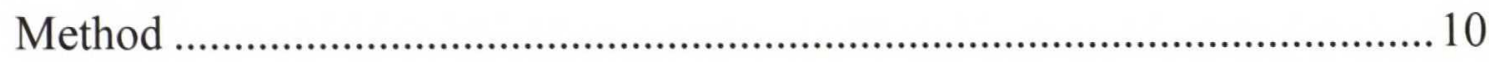

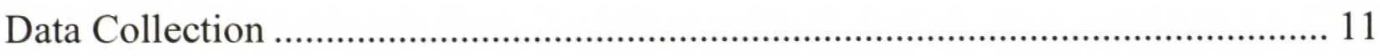

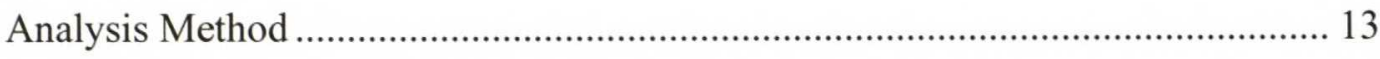

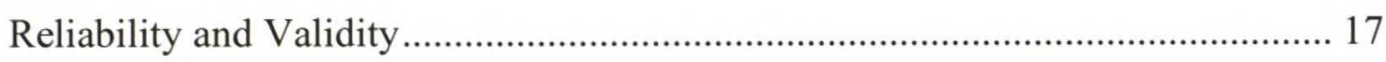

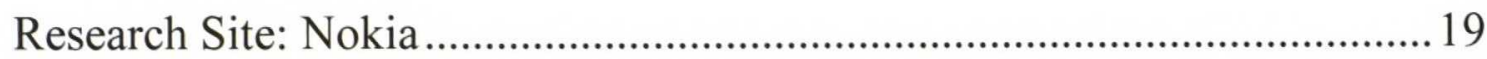

Organizational Identity at Nokia........................................................................... 22

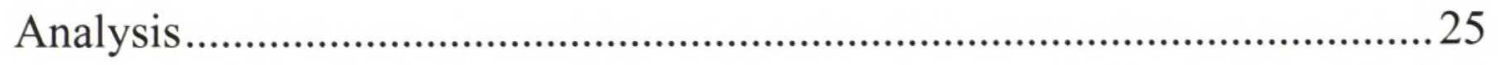

Identity Co-evolution ......................................................................................... 25

Identity and Management Decision Making ........................................................ 40

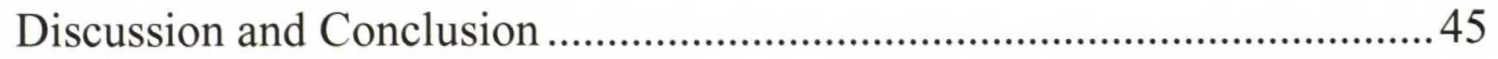

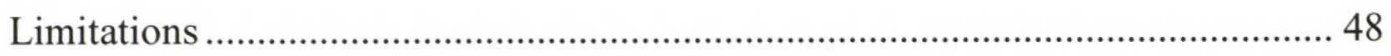

Implications for Theory and Future Research ………………………………....... 48

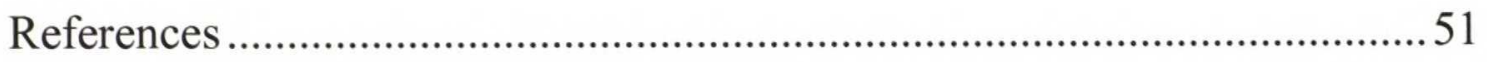




\section{Introduction}

Organizational identity research has occupied one of the most prominent and widely studied niches in the field of organizational behavior for quite some time. This is hardly surprising, since shared views of "who we are" form an important part of the gestalt of an organization, and therefore often have implications for its future. Current research on identities in the organizational context is not, however, exhaustive by any means. The evolution of identities within complex organizational contexts, in particular, has received little attention in extant organizational research. The issue of multiple identity co-evolution is especially salient in diversified multibusiness firms, where distinct identities form at different levels of the organization and affect interfirm relationships and management decision making.

The corporate-business unit relationship has been studied from a strategic (Gupta, 1987), resource sharing based (Gupta \& Govindarajan, 1986) and dynamic capabilities (Galunic \& Eisenhardt, 1996; 2001) perspective, but there seems to be a lack of existing research on the implications that identities have in such relationships. The existence of multiple and differing identities in the subgroups of an organization has been accepted in many grounding studies of organizational identity (Albert \& Whetten, 1985; Ashforth \& Mael, 1989), but their effects on the evolution of the organization as a whole have only been studied from a couple of distinct angles (e.g. Sackmann, 1992; Willem, et al., 2008). Especially, the co-evolution of different identities within organization and their linkages to management decision making has received little attention. 
The purpose of this paper is to extend the current literature on multiple organizational identities by analyzing the different mechanisms that lead to identity coevolution over time. Of specific interest are the processes that lead to the divergence or convergence of these identities and how they vary across organizational levels. Furthermore, the implications of these paths of evolution for managerial decision making during organizational crisis and the subsequent turnaround process are also analyzed.

These aspects of multiple identity evolution and managerial decision making are studied within the context of a Finnish multibusiness firm, Nokia, during the timespan of 1967 to 1993 . The evolution of multiple identities within the focal firm is examined through a detailed qualitative analysis that is based on rich archival data. By employing methods of both induction and deduction, the identities of the different units are mapped throughout the time period, which results in a longitudinal analysis that reveals several key mechanisms behind identity co-evolution and its relationship to managerial decision making.

The findings of the study suggest that co-evolutionary mechanisms vary across organizational levels in terms of both the signals that instigate identity shifts and the nature of those shifts. Furthermore, the results also suggest that this evolutionary process forms an important starting point for managerial decision making in the context of organizational crisis and turnaround by providing various alternatives for future focus and direction. The results are theorized into two frameworks that utilize the evolutionary concepts of variation, selection and retention to explain the evolutionary process of multiple identities and decision making. 


\section{Theory}

\section{Organizational Identity}

Social identity theory (Ashforth \& Mael, 1989) has established that as people come together to form salient groups, they begin to form a collective identity. This identity determines, on both the individual and group level, how members of the group perceive themselves in terms of other groups and the social context (Hogg \& Abrams, 1988; Tajfel, 1981; Tajfel \& Turner, 1979). Organizations represent one type of group to which social identity theory has been successfully applied. In fact, organizational identity, which has been described as the central, distinctive and enduring (CEDdefinition) characteristics of an organization (Albert \& Whetten, 1985; Ashforth \& Mael, 1996; Dutton, et al., 1994; Whetten, 2006), represents one of the most studied and multidimensional paradigms in the field of organizational behavior, with research done on issues such as organizational identity creation (Gioia, et al., 2010; Scott \& Lane, 2000), change (Corley, 2004), threats (Elsbach \& Kramer, 1996) and the concept of disidentification (Bhattacharya \& Elsbach, 2002; Elsbach \& Bhattacharya, 2001; Kreiner \& Ashforth, 2004).

Despite this extensive research, however, many characteristics of organizational identity remain an enigma for organizational theorists. While several studies maintain that in order to gain an understanding of an organization's identity, aspects that are central, enduring and distinctive about the organization should be identified (Albert \& Whetten, 1985; Whetten, 2006), the constituents of organizational identity have yet to be agreed upon. This has led to most empirical work being qualitative and hence somewhat 
subjective in nature. Furthermore, recent research has challenged the traditional notion of an organization's identity being static and enduring, instead arguing that identities within organizations can be susceptible to dramatic changes (Corley \& Gioia, 2004; Gioia, et al., 2000). In addition, other studies have included an organization's image (Dutton, et al., 1994; Gioia, et al., 2000; Hatch \& Schultz, 2002) and reputation (how others see us) (Kreiner \& Ashforth, 2004) or organizational culture (how we do things) (Hatch \& Schultz, 2002) as important components of organizational identity (see Albert (1998) for discussion on definitions and Corley, et al. (2006) for an excellent overview of the concept of organizational identity).

One of the recent developments in the field of organizational identity has been an increased interest in multiple identities, which represent overlapping social categorizations in complex organizations (Albert \& Whetten, 1985; Ashforth, et al., 2008; Ashforth \& Mael, 1996; Foreman \& Whetten, 2002). The notion of multiple identities recognizes the existence of differing beliefs about "who we are" within organizations. As Whetten (2006) points out:

\footnotetext{
...although we don't require the notion of organizational identity to explain multiple, conflicting views of organizations, it is indispensable for explaining multiple, conflicting identity claims in hybrid organizations. (Italics added)
}

According to extant research, however, the role of these differing identities within organizations is ambivalent. On the one hand, multiple identities can often be the source of conflict, which has prompted studies on the management of multiple identities (Balmer \& Greyser, 2002; Balmer, et al., 2009; Pratt \& Foreman, 2000). On the other, 
some studies see multiple organizational identities as beneficial, even necessary for the success and legitimacy of an organization (Sillince \& Brown, 2009). In practice, both views probably hold a seed of truth as factors such as context and organizational characteristics can make multiple identities advantageous for one firm while they debilitate another. Furthermore, multiple identities have also been shown to directly affect boardroom decisions (Hillman, et al., 2008), which further highlights the role of identities as important determinants of organizational outcomes.

The dynamics of identities between different levels of the organization have been described through the concept of nested identities (Ashforth \& Mael, 1989). This approach, consistent with Albert's and Whetten's (1985) idea of the holographic form, views the organizational level identity as an umbrella that fosters identities at lower levels, where each lower level identity is a subset of the set of identities prevalent in the level above. Nested identities offer a useful way of understanding multiple identities, because the model acknowledges the existence of differences across organizational levels while maintaining some requirement of consistency throughout the organization. In terms of organizational outcomes, it has been argued that a high degree of isomorphism or overlap in identities across organizational levels allows the organization to operate more coherently, which translates into better performance (Ashforth, et al., 2011; Riketta \& Nienaber, 2007). Research on the effects of multiple identities on firm performance has so far, however, been limited to conventional organizational forms, leaving highly complex or fragmented organizational structures unstudied.

The identities of business units within multibusiness organizations do not, however, consist solely of nested corporate identities. Instead, business units can contain 
discrete identity elements developed organically over time as well as elements imitated from other sources. Interactions with the parent corporation, other business units and exogenous sources such as industries, institutions or customers form a complex stakeholder network with a plethora of different identities (Brickson, 2005; 2007; Delmestri, 2006; Peteraf \& Shanley, 1997; Scott \& Lane, 2000). These relationships, both internal and external, form an essential part of the identity of an organizational unit, which suggests that constituents of organizational identity are highly complex especially for multibusiness firms. Stakeholder identities have received some interest within current organizational identity research (e.g. Scott \& Lane, 2000), but their role in identity evolution has yet to be studied. Taking into account Dimaggio's and Powell's (1983) seminal paper on institutional isomorphism, which asserts that organizations operating in shared environments tend to become homogenized, it would seem logical that stakeholder identities are highly relevant in the evolution of business unit identities, especially so for those with a high degree of autonomy.

Considering that multiple identities play an important role in organizational decision making and performance, the formation and evolution of those identities has been studied surprisingly little. Most researchers have forfeited this processual approach in favor of a causal perspective, which treats identities as static. The divergence and convergence of multiple organizational identities over time, and their effects on overall organizational evolution and managerial decision making hence offer a relatively novel approach to organizational identity studies.

So far, research linking evolutionary theory and organizational identities has concentrated on the macro level of analysis. For example, Hsu and Hannan (2005) use 
the concept of identities to explain the evolution of organizational populations in terms of ecology, where different organizational identities create variation within the population. A similar approach, however, can be extended to the intraorganizational level, where evolutionary mechanisms of multiple identities within the firm create similar processes of variation, selection and retention. This approach mirrors the evolutionary research performed by Burgelman (1991), which extended conventional ecology models to strategy processes in the intraorganizational context.

Answering the call to utilize organizational identity in conjunction with "other organizational study constructs" (Whetten, 2006), this paper will relate multiple organizational identities with the concept of intraorganizational evolution. The evolution of identities and their implications for managerial decision making will be presented as an evolutionary process of variation, selection and retention. In doing so, the study will increase our understanding of the mechanisms behind identity evolution, the role of stakeholders in that evolution and its implications for managerial decision making, especially during organizational crisis.

\section{Organizational Evolution}

Evolutionary theory has been applied to organizations in a wide variety of contexts and at different levels of the organization. The grounding work done on organizational evolution and ecology (e.g. Aldrich, 1979; Hannan \& Freeman, 1977), which concentrated on organizational populations, has later been complemented with approaches that bring evolutionary theory to intraorganizational settings (see van de Ven \& Poole (1995) for an overview of evolutionary theory). Regardless of the level of 
analysis, most research relies on the original framework of variation-selection-retention (Aldrich, 1979; Cambell, 1969) to explain evolutionary processes in the context of organizations.

Extant research has shown that evolutionary theory and organizational ecology provide useful frameworks for understanding intraorganizational processes. Specifically, such evolutionary approaches have been applied successfully to the process of strategy making (Burgelman, 1991; 1994; Lovas \& Ghoshal, 2000), where strategies represent a selection and retention mechanism from alternative strategic paths arising from internal initiatives that create variation. Such studies have argued that variations are often emergent by nature and originate randomly in different parts of the organization, whereas selection and retention processes are more formal, conscious and centralized to the top management of the organization.

These intraorganizational approaches are, however, far and wide, and have focused solely on explaining strategy processes. Taking into account the wide usage of evolutionary theories at other levels of analysis, the intraorganizational perspective thus seems grossly underused. Since organizations are complex structures often containing distinct divisions or subgroups that form populations, they lend themselves equally well to an evolutionary approach. As Burgelman (1991) showed, the framework of variationselection-retention represents a useful concept for understanding organizational processes that are mixture of emergent behavior and strategic choice. As such, it should logically suit the largely analogous setting of co-evolutionary processes of multiple identities within firms and their implications for managerial decision making. 


\section{Research Questions}

In light of the current theory on organizational identities, this paper will focus on several relevant issues that have both theoretical and managerial implications. Below are outlined two research questions, which summarize some of the identified research gaps and outline the rest of the paper.

Firstly, the paper will address how the identities at different levels of the organization change and interact with each other in order to better understand identity co-evolution in multibusiness firms. This evolutionary process is examined in terms of the convergence or divergence of collective identities, as represented by changes in cognitive distance, which result in the destruction and creation of variance within the organization. This leads to the first research question:

\section{RQ1: How do identities co-evolve at the corporate and business unit levels?}

Secondly, the study will examine the effects of this ongoing evolutionary process on top management decision making during extreme organizational crisis. Specifically, the paper will explore how the degree of isomorphism between these identities, represented by cognitive distance, affects the selection and retention mechanisms of corporate top management during necessary transformation processes. This leads to the second research question:

RQ2: What implications does identity evolution have for top management decision making during crises? 


\section{Method}

The field of strategic management is continuously evolving, with new paradigms emerging while old ones lose popularity. One such change occurred during the 1980s, when the previously predominant organizational form of diversified conglomerates was replaced by a preference for ones based on a single business or related diversification (Davis, et al., 1994). Despite this shift away from the multibusiness form of organization, there still exist plenty of organizations that consist of many, often unrelated, business units, each with their own business logics and cognitions. Furthermore, many conventional organizations consist of salient subgroups dictated by, for example, geography or function. This means that the issue of multiple organizational identities is still relevant for many firms. In order to illustrate the effects of multiple identities on an organization, a case study was performed on a multibusiness firm that is composed of distinctive business units operating in different industries. This allowed for a lucid and sophisticated account of the interactions and transformations of the multiple existing identities across organizational levels as well as through time.

A suitable multibusiness firm that offered ample and accessible data was found in the Finnish telecommunications giant Nokia, which was, prior to its focus on telecommunications in the $1990 \mathrm{~s}$, an archetype of a conglomerate, with businesses ranging from basic industry (pulp \& paper, cables, rubber) to high technology (computers, televisions, mobile telephones, telecom networks). Table 1 summarizes the data collection and analysis methods utilized in the research. 
Table 1 Summary of Data Collection and Analysis Stages

\begin{tabular}{|c|c|c|}
\hline & Stage 1: Identification of identities & Stage 2: Building of evolutionary model \\
\hline Source & Archives of focal company & Archives of focal company \\
\hline \multirow[t]{2}{*}{ Data } & $\begin{array}{l}280 \text { relevant documents between the years } \\
1967 \text { and } 1993 \text { identified from thous ands of } \\
\text { documents }\end{array}$ & $\begin{array}{l}\text { Uncategorized identity claims coded by time, } \\
\text { which had been extracted from } \\
\text { documentation }\end{array}$ \\
\hline & $\begin{array}{l}\text { Included strategic documentation, board } \\
\text { minutes, annual reports, internal } \\
\text { correspondance, long-term planning, travel } \\
\text { documentation }\end{array}$ & $\begin{array}{l}\text { Company context from annual reports and } \\
\text { documentation }\end{array}$ \\
\hline Method & $\begin{array}{l}\text { Inductive methods to determine } \\
\text { characteristics of identity; longitudinal } \\
\text { approach }\end{array}$ & $\begin{array}{l}\text { Deductive methods to categorize identity } \\
\text { claims into relevant domains for analys is } \\
\text { that could be built into an evolutionary model; } \\
\text { processual approach }\end{array}$ \\
\hline Objectives & $\begin{array}{l}\text { Finding statements about who we are and } \\
\text { how we are seen by others which represent } \\
\text { identity claims; coding these claims by } \\
\text { author, unit, year, subject and theme }\end{array}$ & $\begin{array}{l}\text { Building of evolutionary model by forming } \\
\text { visual and conceptual models of identity } \\
\text { changes over time; determining relevant } \\
\text { managerial decisions affected by identity by } \\
\text { comparing identity shifts with organizational } \\
\text { context }\end{array}$ \\
\hline
\end{tabular}

\section{Data Collection}

In order to study the constitution and evolution of the identities at Nokia and its business units, an extensive search for data was performed in the Nokia corporate archives as well as the Central Archives for Finnish Business Records (ELKA). This study was one of the first to gain access to the full archives of the company for the time period in question and is unprecedented in depth on Nokia. The data gathered focused on documents that shed light into how different units within the organization viewed themselves. Furthermore, documents that revealed how each unit saw their role in relation to other stakeholders (industries, other business units and the corporation) were also collected. The extracted material included, but was not limited to, board minutes, annual reports, long-term planning documents, travel reports and internal correspondence. Moreover, the data also included documents containing evidence on the 
identities of, and linkages to, corresponding industries (or strategic groups) in order to understand how external stakeholders affected identity evolution in different units.

A thorough search in the Nokia archives resulted in the identification of 280 relevant documents from a timespan of 1969 to 1993. The emphasis of the documents, however, was on the most pertinent years of Nokia's radical transformation during the 1980s. Together these identified documents comprised a library of over 2000 pages. The available archives contained documents predominantly from Nokia headquarters, the telecommunications divisions as well as the paper division, which meant that the identities of these three were analyzed in most depth. The three units produced a sufficient sample for the study, because it allowed all of the relevant identity relationships to be analyzed. The inclusion of the corporation allowed nested identities to be determined, whereas data on the two business units allowed cross-level identity dynamics to be followed. Moreover, industry related documentation found in the archives of both the telecom and pulp \& paper units provided insight on the role of stakeholder relationships in identity evolution. In order to complement the data, some data on the consumer electronics division was also gathered. Furthermore, the annual reports of Nokia from the years 1970-1993 were analyzed in order to gain an understanding of the prevailing corporate context. The spread of documents across the timespan and divisions can be seen in Table 2 .

Table 2 Summary of Archival Data by Year and Source

\begin{tabular}{|c|c|c|c|c|c|c|c|c|c|c|c|c|c|c|c|c|c|c|c|c|c|c|c|c|c|c|c|}
\hline Documents & \multicolumn{27}{|c|}{ Year } \\
\hline Unit & 1969 & 1970 & 197 & 119 & & 1973 & 1974 & 4197 & & 976 & 1977 & 1978 & 8197 & & 8801 & 1981 & 19821 & 19831 & 19841 & 1985 & 1986 & 1987 & 1988 & 1989 & 1990 & $9911992 \quad 1993$ & Total \\
\hline \begin{tabular}{|l|} 
Corporation \\
\end{tabular} & & 3 & & 6 & 2 & 1 & 2 & 2 & 3 & 2 & 2 & 1 & 1 & 2 & 2 & 2 & 6 & 3 & 2 & 4 & 7 & 18 & 10 & 3 & 9 & 3 & 97 \\
\hline Telecom & & & & & & & & & 1 & 2 & & & & 2 & 3 & 11 & 5 & 13 & 14 & 16 & 19 & 17 & 28 & 24 & 6 & 5 & 166 \\
\hline \begin{tabular}{|l|} 
Paper \\
\end{tabular} & 2 & & & & & 1 & & 1 & & & & 1 & 1 & & & 1 & 3 & 2 & & & & 5 & 1 & & & & 17 \\
\hline Total & 2 & $\overline{3}$ & 3 & 6 & 2 & 2 & & 3 & 4 & 4 & 2 & $\overline{2}$ & 2 & $\overline{4}$ & 5 & 14 & 14 & 18 & 16 & 20 & 26 & 40 & 39 & 27 & 15 & 2 & 280 \\
\hline
\end{tabular}




\section{Analysis Method}

In order to clearly identify the evolution and interactions between the different identities of the organization, the study employed a combination of latitudinal and longitudinal methods. Firstly, the cognitions and multiple identities of the organizational units needed to be determined at several critical points in time. For Nokia, occasions of special importance included significant changes in organizational structure as well as the crisis that the company faced at the end of the 1980s. This cross-sectional analysis of identities at critical inflexion points portrayed the relationship between identity change and organizational transformation in detail. Next, a longitudinal analysis of the evolution of the identities within the organization was performed in order to determine how different identities either converged or drifted apart during the time period under inspection. This evolution was constructed into a historical narrative, which revealed the overall picture of how the central components of the units' identities developed through time. The degree of isomorphism between the identities of different organizational units was denoted by cognitive distance, which represents the difference between the beliefs and shared meanings at the group level (Nooteboom, et al., 2007). It was utilized as a mental and visual model to represent relative differences and similarities in the knowledge spaces and identities of organizational subgroups.

In order to determine the composition of the multiple identities of the organization, the methods of induction and deduction were utilized in alternation. This 'middle ground' was best suited for organizations such as Nokia, for which the number and nature of identities was not known beforehand (Albert \& Whetten, 1985). The rich archival data from the focal organization allowed for certain distinctive characteristics of 
identity data to be extracted without initially categorizing them under extant theoretical organizational identity concepts. Once a rough estimate of the identity components of the different units had been found inductively, they were deductively linked to existing identity theories, such as the CED-definition proposed by Albert and Whetten (1985). Furthermore, the identity claims discovered inductively in the source material were critically evaluated and compared to other claims to ensure consistency and credibility.

The purpose of this alternation between methods was two-fold. Firstly, the initial inductive approach ensured that no relevant data would be overlooked due to the existence of presumptions or constraining definitions (Pettigrew, 1990). Secondly, a critical deductive approach was needed in order to shape the data into relevant categorizations that would allow analysis to be done. Furthermore, this approach also increased the reliability of the data by discarding irrelevant items or outliers that had no impact on the overall results.

Once the material had been gathered, it was analyzed and any relevant information such as the unit, year, writer, subject and theme were coded for each document. Simultaneously, the identities of the different groups were reconstructed by identifying explicit identity statements within the data. In order to be able to concentrate on aspects of identity, only statements that, according to established definitions (Corley, et al., 2006), pertained to organizational identities were included. These were statements about:

1. Who we are? - Claims about who we are form an integral part of identity. These statements include the units' shared beliefs about their own characteristics - the core of what makes the group salient - as well as 
perceptions about their place relative to others within the corporation or the industry.

2. How we are seen by others? - Beliefs about how the unit is viewed by other units, competitors or other stakeholders are an important component of organizational identities, because they help situate a salient group in its context.

This empirical method of identifying organizational identities through the paradigm's two fundamental questions allowed a sidestepping of the undergoing debate on the explicit definition of identity (Albert, 1998). In other words, Nokia's identity was best understood by seeing how the different units of the company saw themselves and each other, not by artificially attempting to categorize each piece of research data as pertaining to identity or not according to criteria that researchers in the field cannot agree upon. This interpretivist approach (see Whetten \& Godfrey, 1998 Chapter 3 for discussion on paradigmatic perspectives) will not settle any ongoing debates about the exact definition of organizational identity. Instead, by attempting to understand how organizational actors see and interpret identity, this paper will produce insights about how identity affects the behavior and actions of organizations.

After the initial data had been gathering by inductive means, methods of deduction were used to refine the data and make it susceptible for analysis. The set of initial identity claims were evaluated based on the grounding definitions of the field, which postulate that the constituents of organizational identity are characteristics that are 
central, enduring and distinctive to the organization (Albert \& Whetten, 1985). This deductive process allowed for a coherent categorization of the identity claims.

The central characteristics of Nokia's units' identities were determined to be those that were prevalent regardless of the author of the text or the type of document in any given time period. Hence, claims of "who we are" that only appeared in one or two documents or were made recurrently by only one author were discarded. In terms of the Corley et al. (2006) conceptualization, centrality was ensured because different authors proved that the claim was shared, whereas its prevalence in all types of documentation ensured that the claim was also central in depth.

The distinctiveness of the identity claims was evaluated by determining whether the claim differentiated the unit from a) the corporation, b) other Nokia units, or c) competitors and other industry players. Hence, assertions such as "we attempt to make profit" or "we are a Nokia unit" were discounted, because they did not describe any distinctive characteristic of the group.

The evaluation of the endurance and continuity of the identity claims posed an interesting problem. Due to several significant incidents during the research period such as the financial crisis of the focal company, which presumably could have altered the identity of its units dramatically, any strict requirements of continuity were removed. This, however, can be justified by the ongoing debate on the issue of identity change in organizational research, where some believe identities to be stable and enduring (Albert \& Whetten, 1985; Whetten, 2006) while others consider identities as susceptible to change (Corley \& Gioia, 2004; Corley, et al., 2006; Gioia, et al., 2000). 
After compiling the identity claims of each unit based on the criteria above, the identities were categorized under broader dimensions, which allowed for the comparison of the multiple identities present at Nokia. The process involved examining the gathered identity claims and determining how they could be aggregated into relevant dimensions for comparison. Despite the possibility of losing some specific details of individual claims, the aggregation was necessary to understand how the identities of different groups affected each other as well as organizational outcomes. Finally, these categorized identities were organized into a narrative, which allowed them to be represented in terms of their evolutionary paths across time.

\section{Reliability and Validity}

One might question the suitability of historical documentation as a representation of an organization's identity, but in some cases explicitly stated identity claims in written documents might actually be more reliable and accurate at representing shared beliefs and identities than personal recollections. Firstly, due to a lack of retrospective bias, archival data can be more representative of how identities were shared by organizational units decades ago. This is especially salient for research that has a long timespan, where a narrative type of approach (Brown, 2006) to identities is applied. Secondly, in large multibusiness firms like Nokia, differences in identities can be identified from how things are presented in documents. In fact, units can deliberately diverge from corporate identities in their written documents in order to increase coherence and isomorphism within the unit. Thirdly, established and consistent manners 
of expressing items in text can be indicative of latent and subconscious identities, which could not be expressed through speech.

In addition to these practical reasons, there are theoretical qualifications for the use of archival data. In their reflection on the current state of organizational identity research, Corley et al. (2006) assert that organizational identity as a concept is so complex that proper methods are contingent on the theoretical approach and the context of the study. Furthermore, the approach of this study is emic, which means that the purpose of the study is not to find any generalizable elements of organizational identity that are common to most organizations. Rather, this study attempts to discover the unique identity elements of the focal company, as written down by its organizational members, and determine how those identities, whatever they were, affected intraorganizational dynamics and outcomes. In terms of the Corley et al. (2006) classification, this paper thus regards organizational identity as a phenomenon that is real (as opposed to a metaphor) and therefore capable of influencing other organizational processes such as managerial decision making. Therefore, the question of whether written identities are exact representations of actual identities is less relevant than how those identity claims evolve and affect each other. Corley et al. (2006) express these considerations with gathering data on organizational identity as follows:

...there is not much existing research that helps map the challenges of operationalizing, assessing, and measuring organizational identity... For example, should you look at the "claims" made by organizational elites, institutional categories, or some other identity component...? Should you...talk to members in different parts of the organization or 
simply "read" the representations of organizational identity? ... when is it sufficient to talk with no one and focus instead on archival data?

This lack of established methods for data collection and analysis in organizational identity research allows for experimentation, which leads this study to use, in the words of Corley et al. (2006), "claims made by organizational elites" found in "archival data".

\section{Research Site: Nokia}

The roots of Nokia can be found in three traditional Finnish companies, which merged in 1967 to form the conglomerate. The oldest, Nokia Ab, which operated in the pulp \& paper industry, had been one of the leading paper firms in Finland ever since it was founded in 1865 . The second was Finnish Rubber Works, also founded in the $19^{\text {th }}$ century, which manufactured rubber boots and tires. The third was Finnish Cable Works, which manufactured cables for domestic and Soviet markets. (Häikiö, 2001)

The merger, which made Nokia a conglomerate operating in three distinct industries, was not executed in order to gain synergies. Instead, the main motivation was for Nokia to gain credibility and size both domestically and abroad (Häikiö, 2001). This meant that, besides some small scale collaborations in, for example, the coating of cables, the business units of the nascent corporation were quite segregated.

In terms of inter-firm collaboration, the situation remained unchanged for most of the 1970s and 1980s. After the merger of 1967, the company was organized into four discrete divisions; rubber, cable, pulp \& paper, and electronics. The divisions had little in common in terms of related operations or synergies, which meant that the corporation 
was managed like a portfolio of separate companies. Due to this segregation, the units developed more on the terms of their respective industries than according to any centralized master plan. Communication with corporate headquarters consisted mainly of routine financial updates and company-wide guidelines on investment, recruiting and general procedures. The mundane nature of corporate-business unit linkages meant that the role of the corporation was mainly administrative through the 1970 s, which resulted in a high degree of autonomy for the units.

The portfolio-based business logic of the corporation continued throughout the first two decades of the merged company. The addition of plastics (1974), engineering (1978), machinery (1982), metal (1982) and chemicals (1983) divisions as well as the acquisition of numerous subsidiaries reinforced this idea of Nokia as a highly diversified conglomerate with an emphasis on basic industries (Nokia Annual Reports, 1970-1993). Nokia's complex structure meant much autonomy for its business units, which were allowed to develop their own business models and strategies within the limits of the corporate investment framework. In the meantime, the corporation focused on responding to economic cycles by modifying its portfolio of businesses.

Towards the second half of the 1980s, however, Nokia's business logic changed due to necessity. Several hazardous acquisitions, declining financial performance and mounting bureaucracy due to the complexity of the firm challenged the company's existing business logic. Nokia's financial troubles began with the large-scale acquisitions of European consumer electronics manufacturers Océanic and SEL, which resulted in a rapid deterioration of performance for the recently added consumer electronics unit (Ruottu, 1996). Subsequently, the company started streamlining its 
operations and divesting businesses according to its new-found focus in technology. This process, however, was not performed rapidly enough and Nokia found itself on the brink of bankruptcy at the end of the 1980s.

Around the turn of the next decade, Nokia divested most of its remaining businesses including the consumer electronics division, whose disastrous performance and severe missteps epitomized the company's difficulties. The drastic measures, a change of management and a new found focus on telecommunications succeeded and the new Nokia completed its remarkable turnaround by becoming a global telecom leader in the second half of the 1990s.

The autonomy of Nokia's business units throughout the 1970s and 1980s and the portfolio mindset of the corporation lend themselves very well to a study on identity evolution. The separate divisions of the conglomerate were often in closer collaboration with organizations in their respective industries than with the other business units of Nokia. In fact, Nokia actively promoted independence of its units and even discouraged collaboration:

When forming joint development units between the industry groups, there must be a clearly seen reason for this formation, because such a joint unit will have an adverse effect on the autonomous business logic of the industry groups. (Nokia Central Administration: Development Procedures at Nokia, 21 September 1971)

Despite holding some common sense of what it meant to be "Nokian", the business units developed their own identities relatively independently. In its conglomerate past, Nokia therefore exemplified the kind of hybrid organization that 
Whetten (2006) refers to, which has multiple, often conflicting identities. This paper will next analyze the co-evolution of these multiple identities and discern what role they played in Nokia's crisis and its swift turnaround.

\section{Organizational Identity at Nokia}

In order to study the evolution of the multiple identities at Nokia, the identity of the corporation, the telecom unit and the pulp \& paper unit (as an illustrative example of Nokia's basic industry) were examined through time. In addition, the identity of the relatively short-lived consumer electronics division was also included due to its important role in the company's crisis and turnaround. During the timespan from 1967 to 1993 , several common identity dimensions emerged from the archival data. These identity dimensions, which represent a somewhat simplified, but nonetheless relevant, categorization of the claims, were prominently present in the documents of each of the groups. For Nokia and its business units, the central and distinctive characteristics that made each of the groups salient, could be divided into four dimensions, which were:

i. Scope of unit's operations in terms of geography

ii. The domain of its operations, for example in terms of industries

iii. The business logic of the unit

iv. The role of the unit in terms of other business units, the corporation and its industry

In other words, at Nokia, units defined themselves based on what markets they operated in, what industries their products belonged to, how they did business and what their relationship was to other organizational actors. These identity characteristics 
obtained through induction were evident throughout the documents and hence form one representation of what identities are made of. Table 3 displays a summary of these identified elements of identity through time. 
Table 3 Summary of Identity Elements at Nokia Units 1987-1993

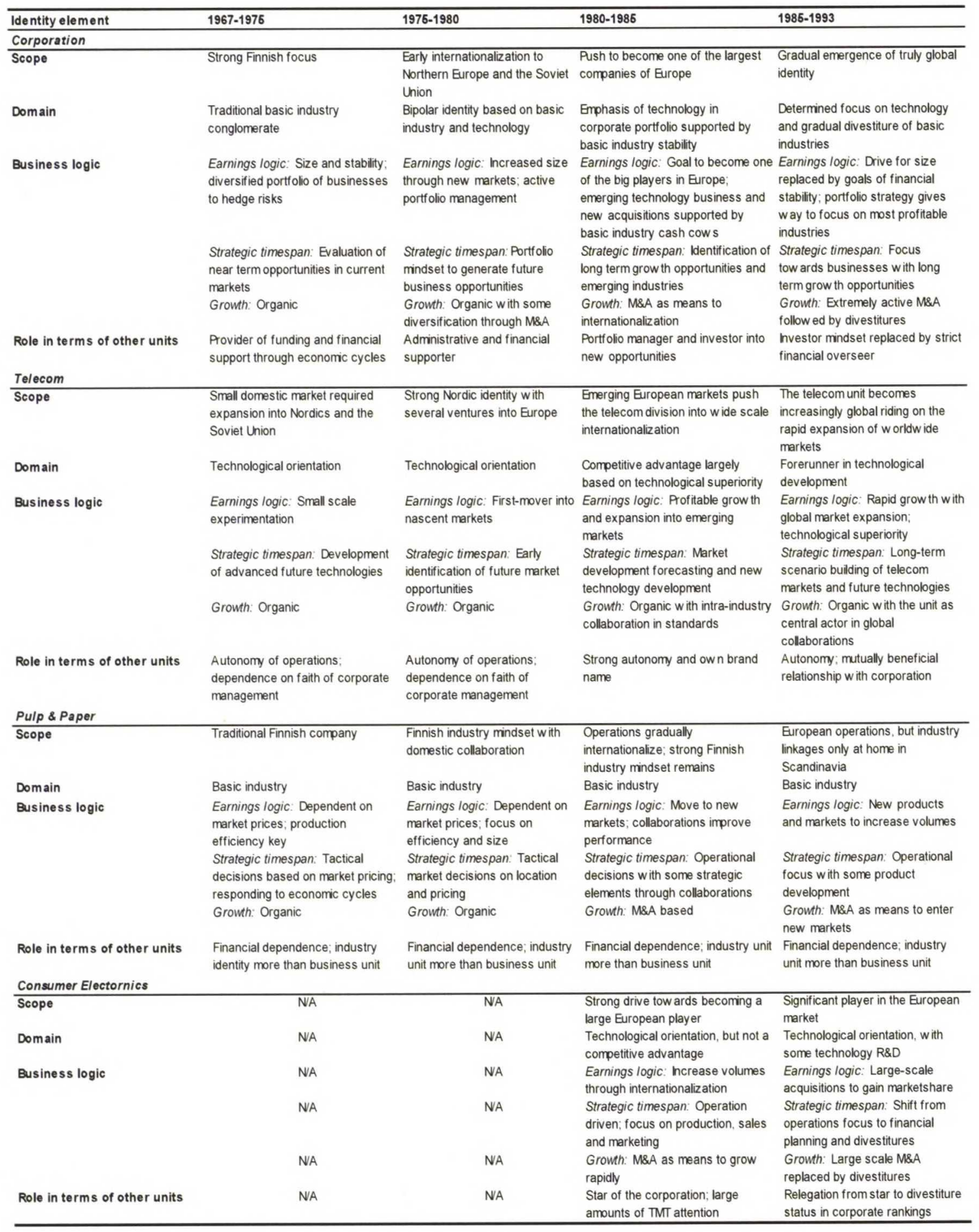




\section{Analysis}

The outlined research questions can now be addressed considering the identified identity dynamics presented in Table 3 . First, the mechanisms behind the coevolutionary processes of identities within Nokia will be studied. Afterwards, the implications of those processes on management decision making and future alternatives during organizational crisis will be examined in detail.

\section{Identity Co-evolution}

Examining the changes in the identities of organizational units over time gives us insights on their co-evolution. The timing and nature of these shifts sheds light into how identity dynamics within multibusiness firms function and what implications these interactions have for organizational outcomes. According to the data, the role of the subunits in terms of the corporation formed an important part of the organizational context that affected this co-evolution. Table 4 summarizes the interrelationships between Nokia's business units and the corporation throughout the study period.

Table 4 Identity in Terms of Role with Corporation

\begin{tabular}{|c|c|c|c|c|c|c|c|}
\hline & & $1967-1970$ & $1970-1975$ & $1975-1980$ & $1980-1985$ & $1985-1990$ & $1990-1993$ \\
\hline \multirow[t]{3}{*}{$\begin{array}{l}\text { Relationship } \\
\text { with } \\
\text { corporation }\end{array}$} & Paper \& Pulp & $\begin{array}{l}\text { Financial } \\
\text { Dependance }\end{array}$ & $\begin{array}{l}\text { Financial } \\
\text { Dependance }\end{array}$ & $\begin{array}{l}\text { Financial } \\
\text { Dependance }\end{array}$ & $\begin{array}{l}\text { Financial } \\
\text { Dependance }\end{array}$ & $\begin{array}{l}\text { Financial } \\
\text { Dependance }\end{array}$ & N/A \\
\hline & Telecom & $\begin{array}{l}\text { Some } \\
\text { Dependence }\end{array}$ & $\begin{array}{l}\text { Some } \\
\text { Dependence }\end{array}$ & Autonomy & $\begin{array}{l}\text { Mutual } \\
\text { Collaboration }\end{array}$ & $\begin{array}{l}\text { Mutual } \\
\text { Collaboration }\end{array}$ & $\begin{array}{l}\text { Mutual } \\
\text { Collaboration }\end{array}$ \\
\hline & $\begin{array}{l}\text { Consumer } \\
\text { Electronics }\end{array}$ & N/A & $\mathrm{N} / \mathrm{A}$ & N/A & $\begin{array}{l}\text { Some } \\
\text { Dependence }\end{array}$ & $\begin{array}{l}\text { Some } \\
\text { Dependence }\end{array}$ & $\begin{array}{l}\text { Some } \\
\text { Dependence }\end{array}$ \\
\hline
\end{tabular}

It shows that all of Nokia's units possessed considerable autonomy in terms of operational and, to some extent, strategic decision making, which meant that identity evolution at the business unit level was not actively constrained by the corporation. The units were, however, dependent on the corporation by other means. The basic industries 
relied on the continuous financial support of the corporation to overcome unfavorable economic cycles and fluctuating resource prices, whereas the telecom unit relied on the initial support of the top management, which fostered the nascent business until it was able to get on its feet. Furthermore, the portfolio management mentality at the corporate level meant that investment decisions and budgeting allocations acted as guidance mechanisms and added some level of dependency. This was especially true for the consumer electronics division, which was very active in making investments and acquisitions. These interrelationships formed the backdrop for identity co-evolution at Nokia. Keeping in mind this context, the co-evolution of multiple identities can be next analyzed. This evolutionary process is best understood by forming graphical representations of how the identity elements of the units changed through time.

\section{Scope of Identity}

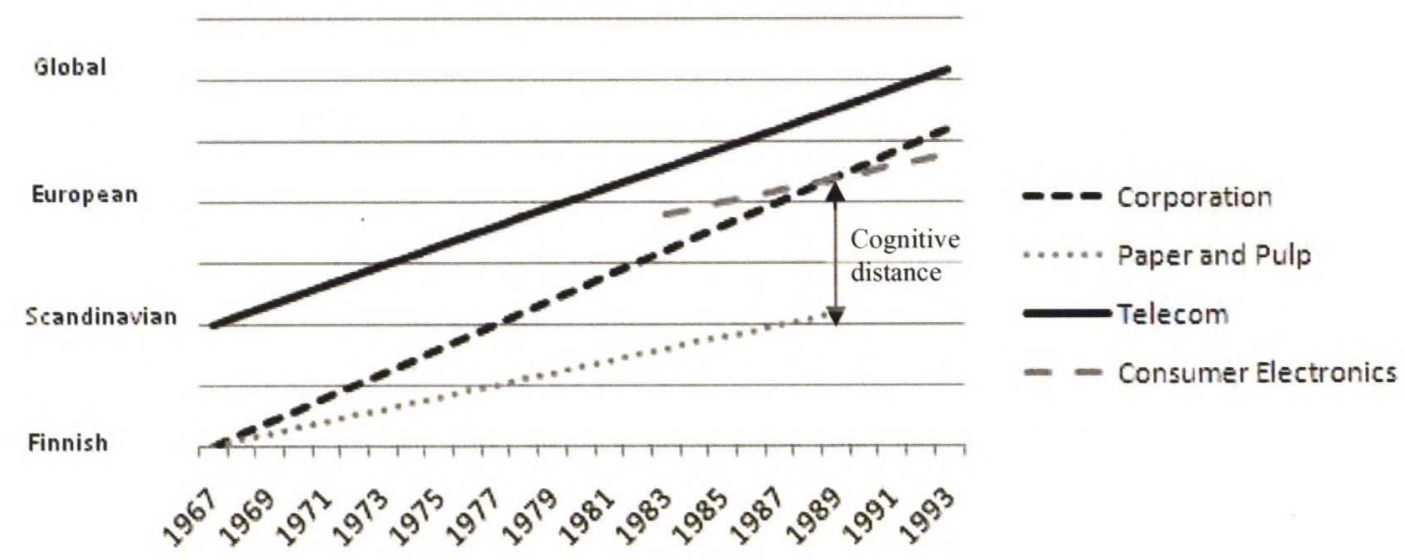

Figure 1- Cognitive distance between Nokia's units in terms of scope

Figure 1 portrays the evolution of the scope dimension of identity at different Nokia units. It shows that the corporation, the consumer electronics unit and the telecom unit contain a strong trend of internationalization, whereas the basic industries saw themselves predominantly as Finnish or, to some extent, Scandinavian players. In terms 
of cognitive distance, the basic industries and the telecom unit remained far apart, whereas the corporate identity clearly converged with the identities of the telecom unit and the consumer electronics unit.

The evolution of the scope of the identities of the business units can be attributed mostly to emergent processes rather than deliberate choice. Immediately after the formation of Nokia in 1967, all of the units within the corporation were centered on its home markets in Finland and Scandinavia. These identities, however, began to diverge, especially during the 1980 s, when differing exogenous factors such as market conditions and industry trends shifted the telecom unit rapidly towards internationalization. Particularly, the large market share of the telecom unit in the highly developed Nordic markets and the nascent nature of global telecom markets were significant in this internationalization. Furthermore, this identity shift was only possible due to the high autonomy of the telecom unit, which allowed the emergent evolutionary process to occur. The international drive of the telecom unit is clearly illustrated in Figure 2, which shows the unit's objectives for international expansion in the mid 1980s. 


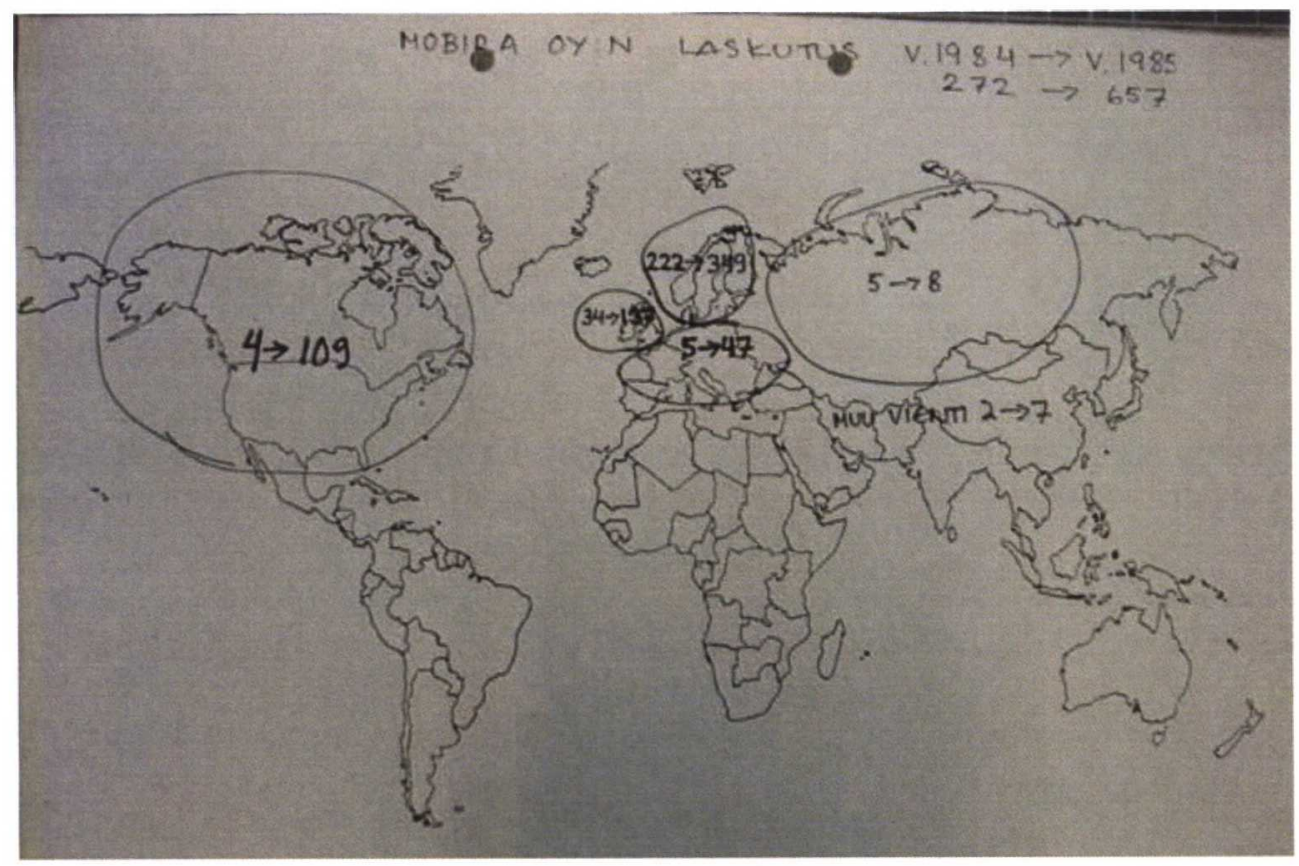

Figure 2 - Mobira Revenues 1984 to 1985 (source: Nokia Archives)

At the same time, the pulp \& paper division's operations were European through the study period, but the unit's identity remained very Finnish. Some of this local identity stemmed from the company's 100 year old roots in Finland, which were regarded as a source of pride. Furthermore, the long tradition of Finnish pulp and paper industry accentuated this view of the unit being based firmly in Finland. In addition, exogenous factors such as the unit's involvement in the Finnpap partnership, which included many of the major domestic players, promoted the retention of its local identity.

At the corporate level, there is a clear shift in the scope of the identity from local to global during the study period. The initial Finnish identity of the corporation was gradually replaced by a European outlook, which was strongly promoted by top management towards the end of the 1980 s. 
We have become a European company. Therefore we ask you to consider, which key personnel, especially from production subsidiaries and the most important sales organizations, should be invited to [the company Strategy Day]. (Nokia Central Administration: Invitation to company Strategy Day, 11 January 1988)

After the recent acquisitions Nokia has become clearly a European company... Many of Nokia's product families can now truly compete in European markets... With some of its products Nokia already is able and aims in the future to compete also on selected overseas markets (cellular phones, cable machinery). (CEO Kari Kairamo: Nokia corporate strategy during the past 10 years and the goals in the 1990s, 1 February 1988)

Compared to the identities of the business units, which were highly contingent on stakeholder identity shifts such as industry trends, collaborations and market conditions, the identity shifts of the top management can be regarded as deliberate rather than emergent. This can be attributed to the lack of direct linkages between the corporation and relevant industries or markets that the management of a multibusiness firm faces, which reduced the amount of exogenous factors that might have affected the corporate identity. Therefore, the identity shift of the top management represents a selection and retention process of the multiple identities of the business units.

In terms of co-evolution, it is notable that the telecom unit saw itself consistently as more international than the other units. As such, the telecom unit acted as a forerunner of internationalization and created organizational variance in terms of scope. This 
divergence by the telecom unit from the prevailing identities of the rest of Nokia later made the internationalization of the corporation possible. The later convergence between the identities of the telecom unit and Nokia's top management represents a gradual selection and retention of the international identity that originated within the telecom unit as variance.

At the same time the cognitive distance between the corporation and its basic industries increased due to a diverging set of identities. This alienation was a result of the local identity elements of the basic industries being actively de-selected by the top management of the corporation.

\section{Domain of Identity}

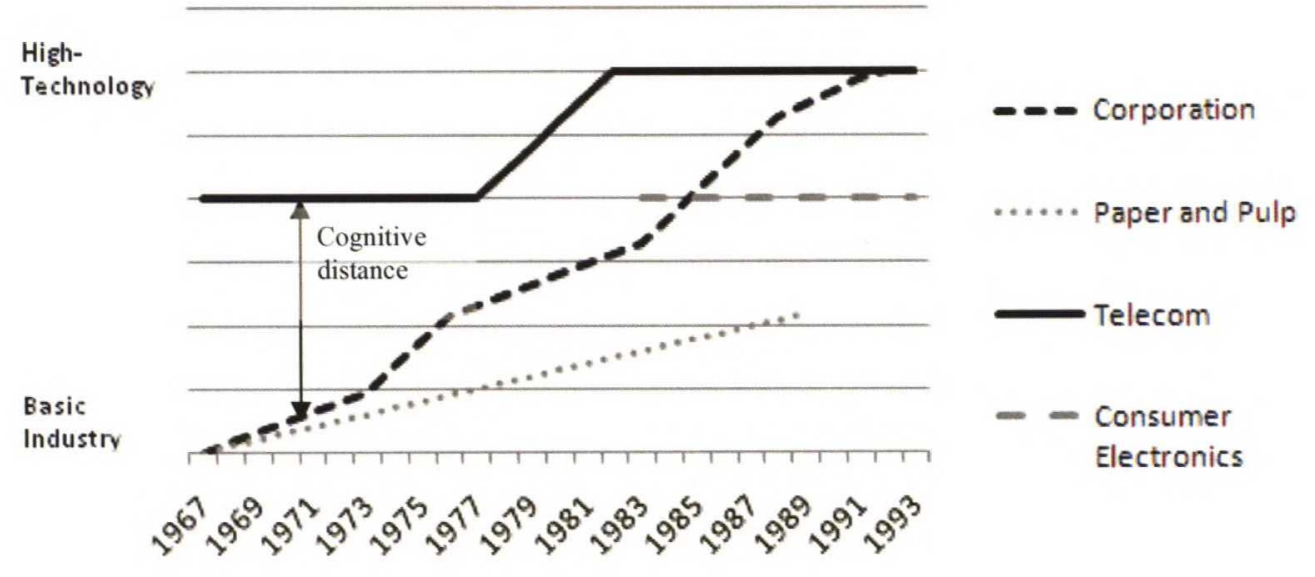

Figure 3 - Cognitive distance between Nokia's units in terms of domain

Figure 3 portrays the co-evolution of the domain of identities at different Nokia units. It interestingly contains many similar trends as those found in the scope of identities in terms of cognitive distance and the gradual convergence of the telecom and top management identities. 
The identity of the telecom unit was very technology oriented from the beginning, which can be attributed to the nature of its business and respective industry. The unit maintained a distinctive technological orientation, which was central to its identity and differentiated it from other Nokia units and even its competitors, who were seen as technologically less developed. This prevailing belief that the unit's competitive advantages lay in its technological superiority was apparent throughout the documentation produced by the unit. This view is illustrated by the following excerpts from the "Strength" columns of various SWOT-analyses made at strategic planning sessions attended by both the management and other employees of the unit:

good quality, keeping up with technological advancements, competitive products, high technological know-how, adaptation of new technology (Mobira SWOT-analysis, 1980)

good products, focus on strategic planning, support of the corporation, competent employees (Long term planning, Cellular division, 1985)

know-how in the telephone business in terms of technology and marketing, ability to develop the unit (Mobira SWOT-analysis, 1985)

The identities of the consumer electronics and pulp \& paper units in terms of domain were similarly dictated by their respective industries. The domain of identity was essentially defined by the business that the units were in, which meant that any management intervention aiming to change that identity would have meant a dramatic shift from the most central elements of the unit. 
The only organizational unit with a clear identity shift in its domain during the time period was the corporation. Nokia's top management regarded the company as a basic industry conglomerate until the mid 1970s, when it shifted to a bipolar business portfolio that regarded electronics as a legitimate growth business, but still relied on the traditional basic industries as the backbone of the corporation. During the $1980 \mathrm{~s}$, however, this identity gave way to an openly technological orientation, as the basic industries were relegated to cash cow status or divestiture. This shift is exemplified by the following statements made by Nokia's top management in the 1980 s.

Finland's largest private sector company is moving further away from its beginnings in the timber industry... Mr Kari Kairamo, president and chief executive of Nokia, sums up the company's present strategy as lying in growth, high technology and internationalization... "The traditional part of the forest industry is dying," says Mr Simo Vuorilehto, managing director of the division. "We're moving further and further away from the forest." (Lance Keyworth, Nokia quits Finland's forests, The Financial Times, February $3^{\text {rd }} 1983$, Nokia Archives)

The 1984 growth figures for the various business sectors reflect the structural changes that have taken place within the Nokia Group, with a growing emphasis toward high-technology and electronics. (Kari Kairamo, President's Survey, Annual Report 1984)

This evolution of top-management identities also resulted in the technology units within Nokia to be regarded as stars and their standings within the corporate portfolio 
rose significantly. Furthermore, the corporation entered new industries, such as consumer electronics, due to this shift in identity towards technology. These management decisions reflect a conscious selection and retention mechanism, which resulted in a convergence of the identities of the top management with that of the telecom and consumer electronics divisions.

\section{Business logic - Timespan}

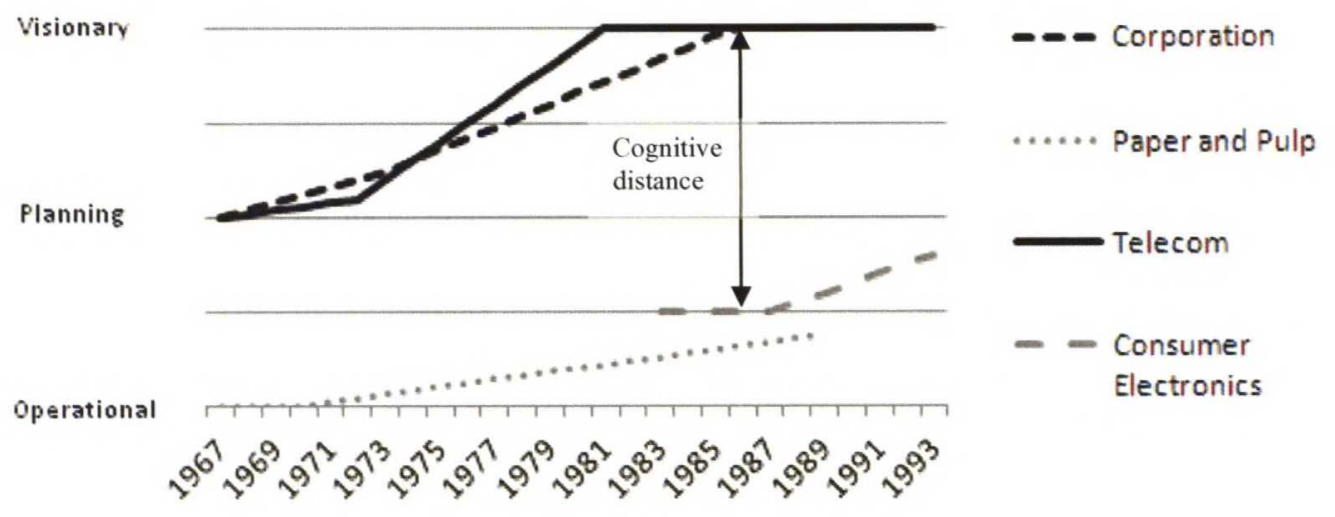

Figure 4 - Cognitive distance between Nokia units in terms of strategic timespan

Figure 4 portrays the evolution of the strategic timespan of the different Nokia units, which reveals several interesting insights. Whereas the corporation and Nokia's telecom unit employed long-term planning procedures spanning five or more years, the basic industries and the consumer electornics unit focused more on current operations. These differences originated largely from the different nature of the industries of the units. Furthermore, the highly autonomic identity of the telecom unit meant that it could not rely on corporate planning in the same way as the consumer electronics and pulp \& paper units, which increased the cognitive distance between the telecom unit and other business units. The evolution of the strategic timespan of the corporation towards long- 
term planning can be attributed to the emergence of a portfolio management mindset within top management in the $1980 \mathrm{~s}$, which relied on the identification of long term opportunities within the corporation business portfolio.

The co-evolution processes presented so far indicate several considerations on the evolutionary mechanisms of identities. Firstly, the source of identity shifts within multibusiness organizations seems to vary across organizational levels, especially so in contexts where business units possess high autonomy. According to the data, identity shifts at the business unit level result from emergent processes that arise from exogenous factors such as market or industry processes (stakeholder identities), while top management identity evolution is a result of conscious selection and retention processes that represent management decision making and interventions. This finding leads to the first set of propositions.

Proposition 1: In multibusiness firms, identity shifts at the business unit level of the organization are predominantly emergent by nature and originate from market and industry processes.

Proposition 2: In multibusiness firms, identity shifts at the corporate level originate predominantly from management interventions in the form of selection and retention processes.

The data on the evolution of multiple identities also produces another interesting finding related to the continuity of identities. According to Albert and Whetten (1985), organizational identities are constituted of the central, enduring and distinctive characteristics of the organization. The data suggests that the scope and domain of 
operations form the most central and distinctive elements of identities within multibusiness firms. The final criterion of endurance, however, is more ambiguous as there seem to be differences across organizational levels regarding the continuity of identities. Specifically, the most central and distinctive characteristics of identities at the business unit level seem to be less susceptible to dramatic changes than those at the corporate level. This finding follows logically from propositions 1-2, because exogenous factors such as industries and markets rarely experience substantial overhauls while conscious top management decisions can result in significant reorientations. The industry linkages and market processes at the business unit level therefore act as anchors that support identity continuity. Furthermore, the strength of this inclination to resist identity change seems to depend on the degree of stability within the unit's respective industry. Nokia's telecom unit operated in a nascent and fast growing market, which contributed to the gradual change in the scope of the unit's identity, whereas the basic industry units operated in established markets that supported maintaining traditional identities. These findings lead to the next proposition.

Proposition 3: In multibusiness firms, business unit identities are less susceptible to change than identities held at the top management level.

The multiple identities at Nokia also contained shared beliefs about the business logic of each unit in terms of growth logic. Figure 5 summarizes the co-evolution of these logics through time. 


\section{Business logic - Growth}

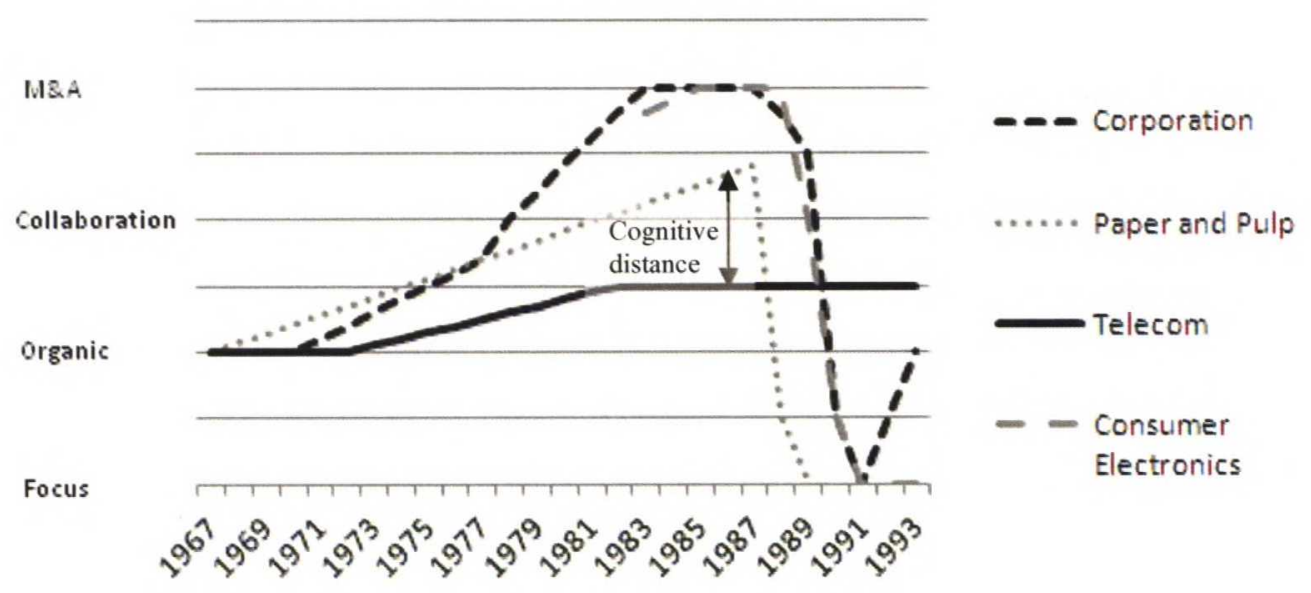

Figure 5 - Cognitive distance between Nokia units in terms of growth logic

At the beginning of the study period, all units shared a similar belief that saw organic growth as the predominant business logic. These beliefs, however, soon began to diverge as the corporation and basic industries began to move towards M\&A as a means for achieving growth while the telecom unit continued to rely on organic growth. It is interesting to note how the growth logic of the basic industries and the consumer electronics division closely followed that of the corporation. This trend seemed to originate from the role of the corporation as a decision maker in terms of investments and budget allocation. The deeply rooted financial dependence of the basic industries on the corporation resulted in an unconscious imitation of the corporate business logic. Similarly, the active investment strategy employed by the Nokia's top management in the consumer electronics market formed a similar dependence relationship, which again resulted in the imitation of growth logic. On the other hand, the high autonomy of the telecom unit, a lack of financial dependence and the laissez-faire attitude of Nokia's management towards the unit allowed it to maintain its organic growth logic. Taking 
into account the evolution of the growth logics and the role of the business units in terms of the corporation presented earlier, a new set of propositions can be presented:

Proposition 4: A financial dependence relationship will increase the likelihood of a business unit imitating a shift in the growth logic of its parent.

Proposition 5: A greater degree of autonomy held by a business unit will make it less likely for that unit to respond to a shift in the growth logic of its parent.

Figure 6 provides three snapshots of the overall evolution of the multiple identities at Nokia. The degree of overlap between the spheres of the corporation and the business units represents how nested the identities of the units were within the umbrella of the corporate identity. Moreover, the cognitive distances between the units are represented by the distances between the dots at the centers of the spheres. The illustration clearly shows that the identity of the corporation converged with that of the telecom unit throughout the time period. Simultaneously, the evolutionary process resulted in the corporate identity drifting further away from the basic industries and, later, the consumer electronics division.

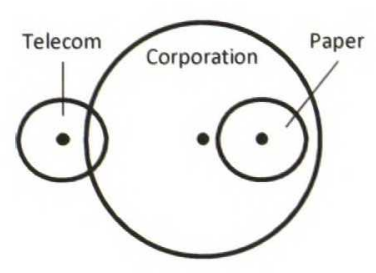

1975

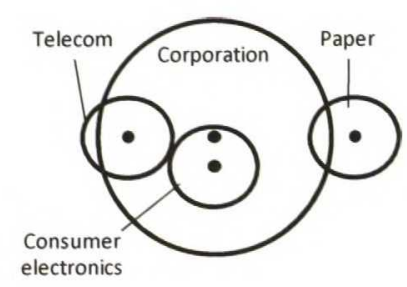

1985

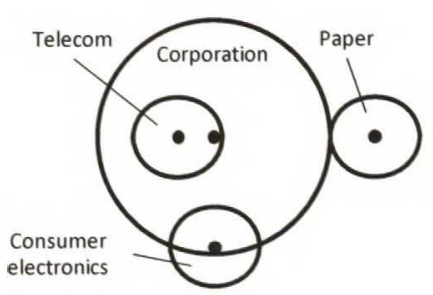

1990

Figure 6 - Evolution of nested identities and cognitive distance 
Taking a more holistic approach to identity co-evolution, the evolutionary process can be described in terms of the mechanisms of variation, selection and retention, which ultimately resulted in identity convergence or divergence, represented by changes in the cognitive distance between the units. The discrete identities of the business units of a multibusiness firm were shown to be relatively continuous and dependent on exogenous factors. These differing identities created variation within the corporation, which provided alternatives for the evolution of top management identities and varying avenues of strategic direction. This selection and retention process occurring at the corporate level was manifested in management interventions in the form of investment decisions and changes in prevailing business portfolio rankings. The following illustrative quote demonstrates this role.

At the corporate level... strategic planning aims to determine a) the need to change and develop the operating structure of the corporation (new business ideas, divestments), b) the focus areas and investment targets... At the business unit level...the goal of strategic planning is to a) determine the strategic business areas (SBA) and segments that the unit will operate in, b) determine the competitive advantages (for example cost structure, new technology, marketing) on which the units success will be based on...(Strategic Planning Guidelines, CEO Kari Kairamo, 1985, original emphasis)

Moreover, Figure 7 exemplifies the internal rankings of businesses performed at the corporate level at Nokia. It shows that Nokia's top management saw the telecom business as a star of the business portfolio towards the end of the $1980 \mathrm{~s}$, while the basic 
industries were seen to possess mediocre future possibilities at best. This ranking process represents an active selection and retention mechanism, which led Nokia's top management to choose the international and technological identities prevalent in the telecom unit as their own at the time. Furthermore, these identity choices formed a positive feeback loop, which, in turn, reinforced the prevalence of international and technological characteristics at the top of the rankings.

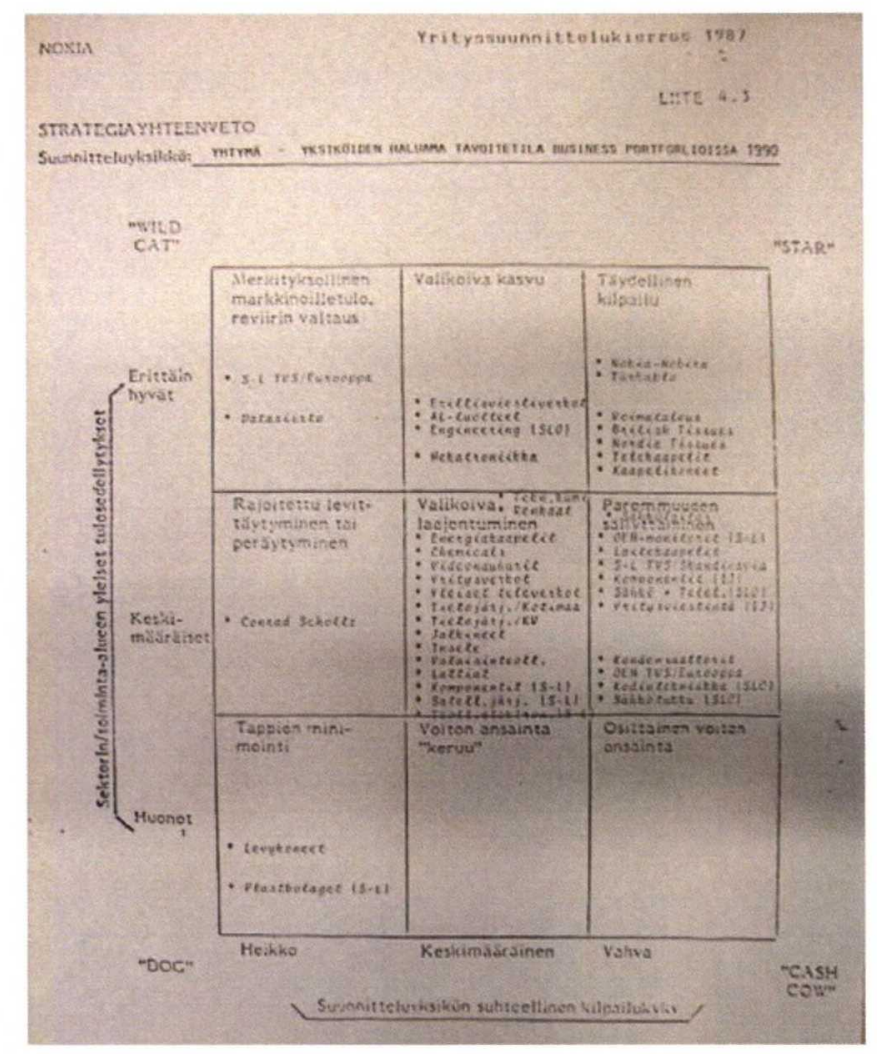

Figure 7 - Nokia Business Portfolio in a BCG-matrix (source: Nokia corporate planning round 1987, Nokia Archives)

Figure 8 summarizes these fundamentally different co-evolutionary mechanisms between organizational levels. While evolution at both the business unit and top management level ultimately leads to changes in cognitive distances, the signals that instigate identity evolution are different. Furthermore, at the business unit level the process is predominantly emergent by nature and based on natural variation, whereas at 
the top management level identity evolution is more conscious and can result in identity convergence or divergence through a selection and retention processes.

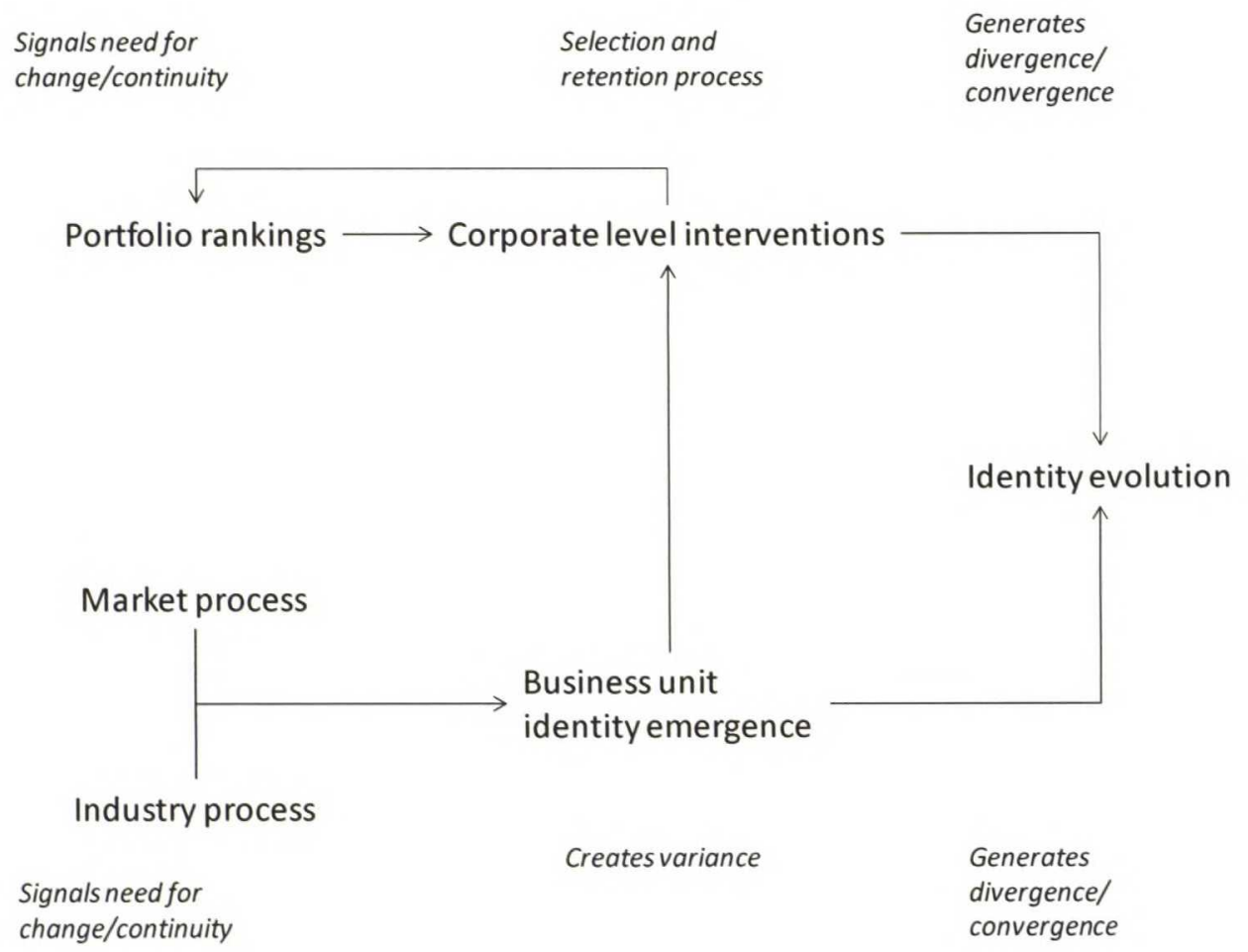

Figure 8 - Identity co-evolution process in multibusiness firms

\section{Identity and Management Decision Making}

The evolutionary timelines introduced in the previous section show that identities tend to be static during the normal course of organizational activities. Shifts in identities at Nokia occurred slowly, because the signals for change originated from exogenous processes or rankings that evolved gradually. These findings are consistent with most of the grounding research on organizational identities, which sees shifts in organizational identity as lengthy and incremental processes (Albert \& Whetten, 1985). The data on Nokia, however, also suggests that severe organizational stress can instigate rapid identity changes at the top management level. This finding mirrors the research of 
Corley and Gioia (2004), which found that identities are susceptible to dramatic changes in rapidly changing organizational contexts. Furthermore, the co-evolutionary process occurring before such crises seems to have implications for top management decision making and possible future alternatives during the crises.

The radical identity change at the top management level is clearly apparent in Figure 5 presented earlier, which shows how the M\&A oriented growth logic within the corporation and many of the business units was quickly replaced by a focus logic towards the end of the 1980s. This rapid change was instigated by a severe financial crisis, which demonstrated the failure of the previous logic and signaled a need for rapid change. This overhaul of existing beliefs was, however, instigated by necessity rather than insightful management decision making, which highlights the role of severe organizational stress as a catalyst for identity change. In more formal terms:

Proposition 6: Severe organizational stress can act as a catalyst for radical identity reorientation, which would not be possible through a natural evolutionary process.

Nokia's entry into the consumer electronics business also reveals interesting mechanics behind identity evolution and top management decision making. The decision made by Nokia's management to enter the new business in the 1980 s was consistent with the corporate identity, because consumer electronics a) represented a technological industry, b) allowed the company to reinforce its European identity, and c) promised growth by means of M\&A, which was the prevalent growth logic held by Nokia's management. The unit could be positioned highly in the portfolio rankings and seemed 
to be perfectly aligned with the identity of the company, which resulted in a short perceived cognitive distance that supported the decision to make large subsequent investments in the business. Nokia's acquisitions of SEL and Océanic meant a high commitment to the business and marked the company's entry into a European consumer electronics market that was highly competitive and plagued by overcapacity, which actually made it unattractive in terms of business opportunities (Ruottu, 1996). Thus the decision that was motivated by a perfect internal fit in terms of the prior identity evolution of the corporation turned out to be a severe mistake in management decision making. The data therefore suggests that high identity isomorphism, as seen and interpreted by the management, can have adverse effects on organizational outcomes when those beliefs override sound logic and lead to decisions that lean too heavily on intuition. Put more formally:

Proposition 7: A short perceived cognitive distance with a unit can result in adverse top management selection mechanisms that are based on identity alignment rather than sound logic.

As Nokia's financial crisis escalated, the variation created by the multiple identities within the business units also provided an opportunity for management decision making that allowed the corporation to begin a turnaround process. Severe organizational distress signaled that some of the beliefs held by the top management had lead to mistakes in decision making, which, in turn, instigated a rapid change in the identity of the corporation. This management intervention resulted in an active identity reorientation that challenged what the central and distinctive characteristics of the 
company were. In Nokia's case, the portfolio logic and reliance on M\&A for growth, which had formed an integral part of top management identities, but had led to the crisis, were rapidly overhauled in a process of de-selection. This decision resulted in a focus strategy that required a selection of one business as the identity of the future Nokia, while other businesses would be divested. The previous divergent processes of identity evolution, however, provided several viable options for the corporation. The telecom unit offered several identity elements that were shared by the top management (international, technological), while others required a shift from current identities (organic growth). Conversely, a shift back to the basic industry identities would have required a radical shift in all current identity elements, whereas a focus on consumer electronics would not have challenged any of the prevailing beliefs that had led to mistakes in decision making.

These observations have interesting implications for organizational turnaround processes. Firstly, divergent evolutionary paths within multibusiness firms result in multiple identities that can provide various alternatives for a corporation during organizational reorientation. This, however, requires that organizational units are given sufficient autonomy to develop variation in terms of identity evolution. Secondly, Nokia's remarkable turnaround suggests that an optimal top management choice for future direction is to realign the corporate identity towards an existing business, which carries some common elements with the current corporate identity, but also requires sufficient change to lead to a legitimate turnaround. This implies that there is an optimal cognitive distance between the corporate identity and the chosen alternative for focus, which is represented by Figure 9 . 


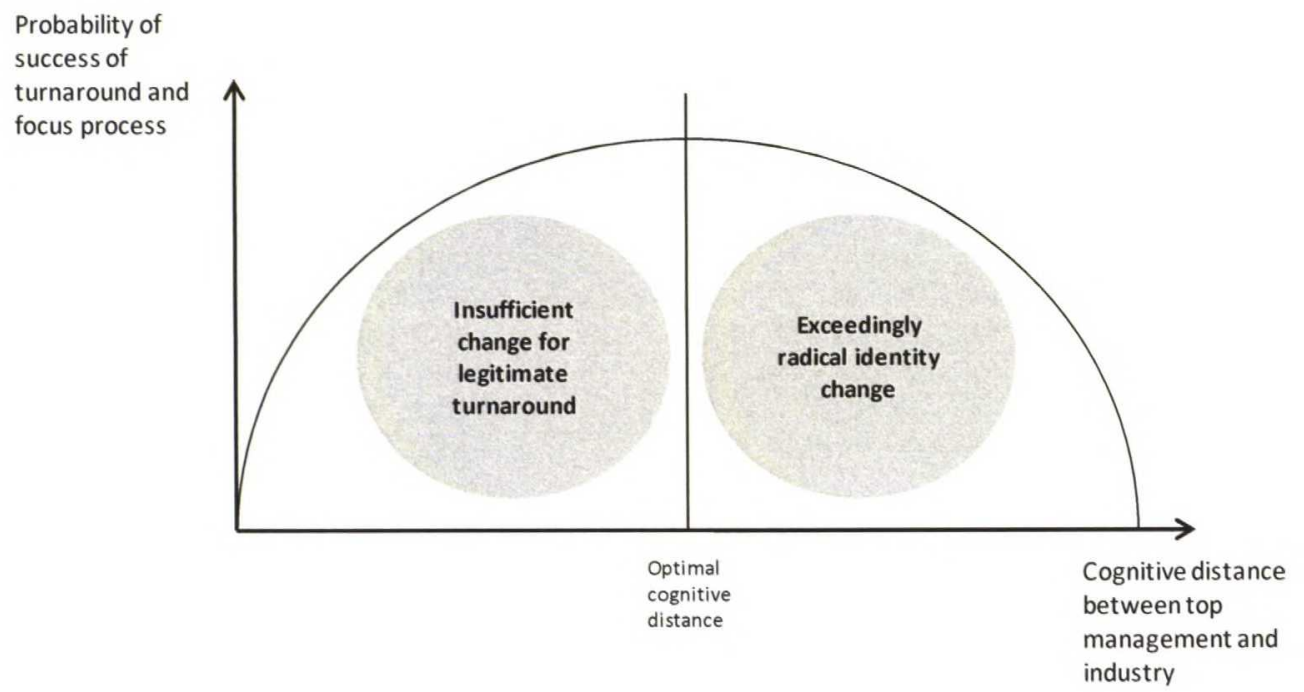

Figure 9 - Optimal cognitive distance in a turnaround and focus process

These findings lead to the final two propositions:

Proposition 8: Given enough autonomy, the divergent identity

evolution processes within the business units of a multibusiness firm

can provide viable alternatives for corporate reorientation during

crises.

Proposition 9: During a turnaround and focus process, $a$

multibusiness firm will have the greatest chance of success by focusing

on an industry that has some common identity elements, but also

requires a sufficient amount of identity shifts to legitimize the

turnaround.

Together these findings on the role of identity during organizational distress reveal several causal mechanisms that affect managerial decision making. The ongoing evolutionary process of identities (Propositions 1-5) seems to form the starting point for managerial decision making during crisis by providing alternative future paths through 
variation. These decisions represent an active selection and de-selection process, where the probability of success depends on the amount of common identity elements or, in other words, the cognitive distance between the corporate identities and the identities of the focus unit. These findings are summarized by Figure 10.

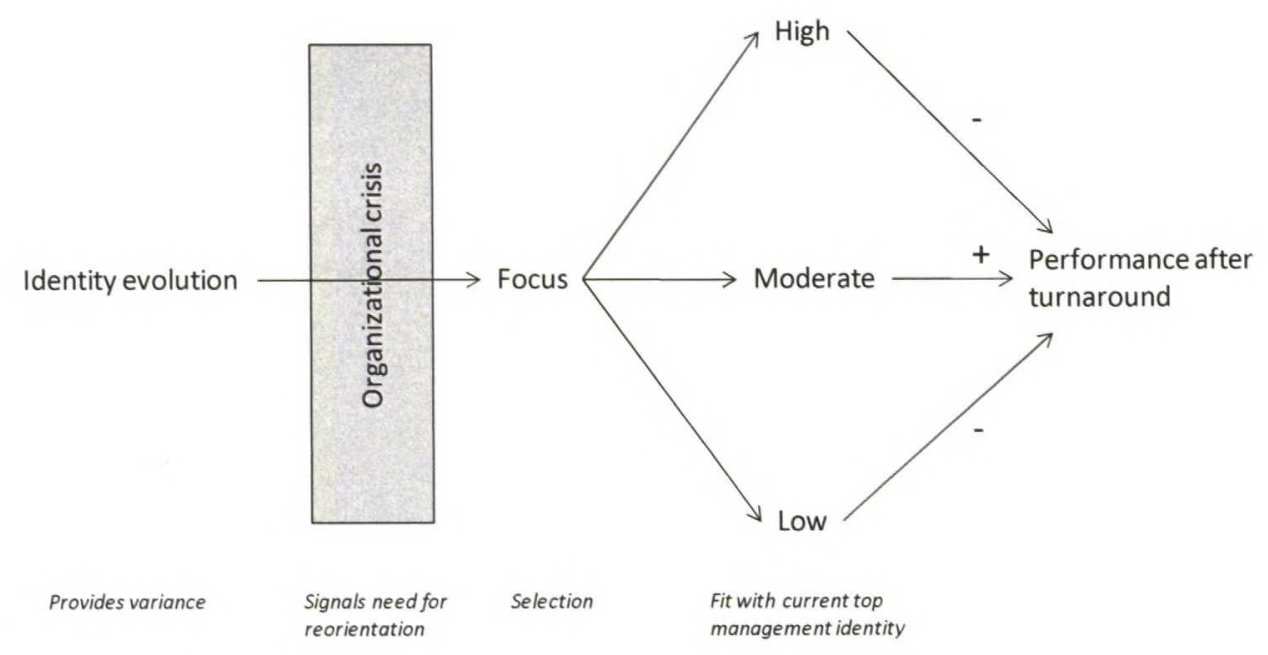

Figure 10 - Managerial decision making mechanisms during crisis

\section{Discussion and Conclusion}

This paper on the multiple identity evolution provides several important implications for organizational identity research. The evolutionary process outlined in Propositions 1 through 5 provides understanding of the signals and mechanisms that lead to the divergence and convergence of multiple identities within complex organizations. It shows that identities at the business unit level evolve predominantly due to exogenous processes and are emergent by nature. Conversely, corporate level identity evolution is more deliberate and based on management decisions in the form of selection and retention processes actualized through mechanisms such as corporate rankings. As such, the findings of the study largely mirror the evolutionary mechanisms found in the context of strategy formation (Burgelman, 1991; Lovas \& Ghoshal, 2000). The results of 
the study also indicate that multiple identities within organizations differ in terms of their continuity, which suggests that active identity management within corporations is limited to the top management level, where identities are susceptible to conscious changes. Furthermore, the findings suggest that the cognitive distance and autonomy between the corporation and its business units affects the co-evolution of their identities. More specifically, it seems that dependence relationships encourage the convergence of identities and reduce organizational variance, while autonomy results in the opposite.

These findings extend the current literature on organizational identity by revealing new dynamics behind identity co-evolution, which allow for a better understanding of why identities converge and diverge within organizations over time. Furthermore, the proposed framework clarifies the causal mechanisms behind identity interactions and summarizes some of the internal and external forces that lead to identity evolution.

The second part of the analysis, which consists of Propositions 6 through 9, studied the effect of multiple identities on managerial decision making in the context of organizational crisis and the subsequent focus and turnaround process. The findings of the study show that top-management identities shifted radically within a relatively short period of time due to severe organizational distress. This supports the notion held by some organizational theorists (Corley \& Gioia, 2004; Gioia, et al., 2000) that identities are susceptible to rapid overhauls in dramatically changing organizational contexts. Furthermore, the managerial decision making mechanisms during such a crisis represent a selection and retention process, which depends on the previous evolution of the identities at different levels of the organization. The variation created by diverging 
business unit identities proves beneficial in the focus and turnaround process of a firm by offering several viable future directions. The probability of success of this selection and retention process seems to depend on the cognitive distance between current top management identities and the identity of the selected business. Furthermore, the optimal cognitive distance appears to require a legitimate change in current management identities, but also needs to provide some consistency by maintaining some central characteristics. Nevertheless, the study also revealed that a short perceived cognitive distance between the top management and a business unit can distort these selection mechanisms and increase the risk of mistakes in strategic decisions.

These findings on the interrelatedness of identity evolution and management decision making offer novel perspectives on the implications of multiple identities within organizations. In terms of the ongoing debate about the positive (e.g. Sillince \& Brown, 2009) or negative (e.g. Pratt \& Foreman, 2000) effects of multiple identities on organizational outcomes, the findings of the study indicate that in diversified organizations multiple identities can be beneficial, because they encourage varying business logics that can instigate rapid organizational change. This challenges the view that a high degree of isomorphism between the identities of an organization is desirable (Ashforth, et al., 2011). Particularly, it seems that multiple identities can create necessary variation within the organization, which can provide alternative directions for change during a turnaround process, where beliefs held by the management need to change rapidly. On the other hand, some overlap is essential in order to ensure organizational coherence, which enables increased performance (Ashforth, et al., 2011). These findings also correspond well to the existing research done on cognitive distances, 
which has suggested that the optimal cognitive distance between firms follows an inverted U-shaped relationship (Nooteboom, et al., 2007; Sebestyén, 2008; Wuyts, et al., 2005).

\section{Limitations}

There are, of course, several limitations to the methods and analysis of the study that need to be stated. Firstly, the data is based on written records extracted from archives, which raises several considerations. Despite being relatively free of bias, written data is never as sophisticated and intricate as spoken accounts, which means that some latent or less obvious identities might have been overlooked. Furthermore, the method relies on identity claims in order to construct a longitudinal representation of identity evolution. This can be problematic, because one cannot be sure that identity claims represent actual identities accurately.

The analysis of the data also raises several questions, which relate to its qualitative nature. The perceived overlaps and cognitive distances are merely subjective representations of how the researcher interpreted the degree of isomorphism between the multiple identities. Furthermore, claims of causality within the study have not been rigorously tested, which might mean that causality is assumed where only correlation exists.

\section{Implications for Theory and Future Research}

The study also provides some implications for the wider context of organizational identity research. Firstly, it offers a novel perspective to the ongoing debate about the definitions of organizational identity. Due to the subjective nature of 
shared beliefs and the different perspectives on the nature of identities, there are no established definitions or methods on how organizational identity research should be performed (Corley, et al., 2006). Most studies still rely on the traditional CED-definition of organizational identity introduced by Albert and Whetten (1985) over two decades ago, which, despite being very useful, is quite vague and difficult to operationalize in practice. The research methods used in this study provide a novel way of viewing organizational identities by suggesting that they are characterized by four dimensions. The scope of operations entails the shared beliefs about the markets and geography of operations. The domain of operations consists of the characteristics or ontologies of their operations in terms of industries or products. The shared beliefs about how to achieve organizational goals form the business logic component of identity. Finally, the role of the unit, in terms of other organizational actors or stakeholders, is important to organizational identity, because it increases the saliency of the group by creating well defined boundaries.

Furthermore, the usage of archival data as a primary source represents a novel approach to organizational identity research, since most extant organizational identity research has relied on interviews or questionnaires in order to make sense of shared beliefs. This study, however, indicates that archival data can be equally suitable for the analysis of organizational identities. By utilizing written data from archives, the evolution of identity claims can be studied without the problems of retrospective bias. Moreover, archival written data allows a better understanding of the evolutionary mechanisms of the identities, because they can be regarded as narratives with a temporal dimension (Brown, 2006). 
In addition, the paper answers the call to utilize organizational identity with other organizational study constructs (Whetten, 2006) by relating collective identities to the concept of organizational evolution. It shows that the usage of organizational identities in combination with the theory of organizational evolution provides a useful framework to conceptualize the complex processes of identity evolution and managerial decision making.

The area of multiple identities offers venues for ample further research. Firstly, the research method based on archival data utilized in this study could be further tested in order to determine whether it is as useful as it seems. Moreover, research on the dynamics of multiple identities within less diversified, but otherwise heterogeneous, firms would be required to validate some of the findings of this study. Despite the vast amounts of research on organizational identities, the concept is complex enough to allow for the continuous usage of new approaches or perspectives that can increase our understanding of them. 


\section{References}

Albert, S. 1998. The Definition and Metadefinition of Identity.In Whetten, D. A. \& P. C. Godfrey, editors, Identity in Organizations. Building Theory Through Conversations. Thousand Oaks: Sage Publications.

Albert, S \& D. A. Whetten. 1985. Organizational identity.In Cummings, L. L. \& B. M. Staw, editors, Research in Organizational Behavior. Greenwich, CT: JAI Press.

Aldrich, H. 1979. Organizations and Environments. Englewood Cliffs, NJ: Prentice Hall.

Ashforth, B. E., S. H. Harrison, \& K. G. Corley. 2008. Identification in organizations: An examination of four fundamental questions. Journal of Management, 34(3): 325-74.

Ashforth, B. E. \& F. Mael. 1989. Social Identity Theory and the Organization. Academy of Management Review, 14(1): 20-39.

Ashforth, B. E. \& F. A. Mael. 1996. Organizational identity and strategy as a context for the individual. Advances in Strategic Management, 13: 19-64.

Ashforth, B. E., K. M. Rogers, \& K. G. Corley. 2011. Identity in Organizations: Exploring Cross-Level Dynamics. Organization Science, 22(5): 1144-56.

Balmer, J. M. T. \& S. A. Greyser. 2002. Managing the multiple identities of the corporation. California Management Review, 44(3): 72-86.

Balmer, J. M. T., H. Stuart, \& S. A. Greyser. 2009. Aligning Identity and Strategy: Corporate Branding at British Airways in the Late 20th Century. California Management Review, 51(3): 6-23.

Bhattacharya, C. B. \& K. D. Elsbach. 2002. Us versus them: The roles of organizational identification and disidentification in social marketing initiatives. Journal of Public Policy \& Marketing, 21(1): 26-36.

Brickson, S. L. 2005. Organizational identity orientation, forging a link between organizational identity and organizations' relations with stakeholders. Administrative Science Quarterly, 50(4): 576-609.

Brickson, S. L. 2007. Organizational identity orientation: The genesis of the role of the firm and distinct forms of social value. Academy of Management Review, 32(3): 864-88.

Brown, A. D. 2006. A narrative approach to collective identities. Journal of Management Studies, 43(4): 731-53. 
Burgelman, R. A. 1991. Intraorganizational Ecology of Strategy Making and Organizational Adaptation: Theory and Field Research. Organization Science, 2(3): 23962.

Burgelman, R. A. 1994. Fading Memories - a Process Theory of Strategic Business Exit in Dynamic Environments. Administrative Science Quarterly, 39(1): 24-56.

Cambell, Donald T. 1969. Variation and Selective Retention in Sociocultural Evolution. General Systems, 14: 69-85.

Corley, K. G. 2004. Defined by our strategy or our culture? Hierarchical differences in perceptions of organizational identity and change. Human Relations, 57(9): 1145-77.

Corley, K. G. \& D. A. Gioia. 2004. Identity ambiguity and change in the wake of a corporate spin-off. Administrative Science Quarterly, 49(2): 173-208.

Corley, K. G., C. V. Harquail, M. G. Pratt, M. A. Glynn, C. M. Fiol, \& M. J. Hatch. 2006. Guiding organizational identity through aged adolescence. Journal of Management Inquiry, 15(2): 85-99.

Davis, G. F., K. A. Diekmann, \& C. H. Tinsley. 1994. The Decline and Fall of the Conglomerate Firm in the 1980s - the Deinstitutionalization of an Organizational Form. American Sociological Review, 59(4): 547-70.

Delmestri, G. 2006. Streams of inconsistent institutional influences: Middle managers as carriers of multiple identities. Human Relations, 59(11): 1515-41.

Dimaggio, P. J. \& W. W. Powell. 1983. The Iron Cage Revisited - Institutional Isomorphism and Collective Rationality in Organizational Fields. American Sociological Review, 48(2): 147-60.

Dutton, J. E., J. M. Dukerich, \& C. V. Harquail. 1994. Organizational Images and Member Identification. Administrative Science Quarterly, 39(2): 239-63.

Elsbach, K. D. \& C. B. Bhattacharya. 2001. Defining who you are by what you're not: Organizational disidentification and the national rifle association. Organization Science, 12(4): 393-413.

Elsbach, K. D. \& R. M. Kramer. 1996. Members' responses to organizational identity threats: Encountering and countering the Business Week rankings. Administrative Science Quarterly, 41(3): 442-76.

Foreman, P. \& D. A. Whetten. 2002. Members' identification with multiple-identity organizations. Organization Science, 13(6): 618-35. 
Galunic, D. C. \& K. M. Eisenhardt. 1996. The evolution of intracorporate domains: Divisional charter losses in high-technology, multidivisional corporations. Organization Science, 7(3): 255-82.

Galunic, D. C. \& K. M. Eisenhardt. 2001. Architectural innovation and modular corporate forms. Academy of Management Journal, 44(6): 1229-49.

Gioia, D. A., K. N. Price, A. L. Hamilton, \& J. B. Thomas. 2010. Forging an Identity: An Insider-outsider Study of Processes Involved in the Formation of Organizational Identity. Administrative Science Quarterly, 55(1): 1-46.

Gioia, D. A., M. Schultz, \& K. G. Corley. 2000. Organizational identity, image, and adaptive instability. Academy of Management Review, 25(1): 63-81.

Gupta, A. K. 1987. Sbu Strategies, Corporate-Sbu Relations, and Sbu Effectiveness in Strategy Implementation. Academy of Management Journal, 30(3): 477-500.

Gupta, A. K. \& V. Govindarajan. 1986. Resource Sharing among Sbus - Strategic Antecedents and Administrative Implications. Academy of Management Journal, 29(4): 695-714.

Hannan, M. T. \& J. Freeman. 1977. Population Ecology of Organizations. American Journal of Sociology, 82(5): 929-64.

Hatch, M. J. \& M. Schultz. 2002. The dynamics of organizational identity. Human Relations, 55(8): 989-1018.

Hillman, A. J., G. Nicholson, \& C. Shropshire. 2008. Directors' multiple identities, identification, and board monitoring and resource provision. Organization Science, 19(3): 441-56.

Hogg, M. A. \& D. Abrams. 1988. Social Identifications: A Social Psychology of Intergroup Relations and Group Processes. London: Routledge.

Hsu, G. \& M. T. Hannan. 2005. Identities, genres, and organizational forms. Organization Science, 16(5): 474-90.

Häikiö, M. 2001. Fuusio: Yhdistymisen kautta suomalaiseksi monialayritykseksi 1865 1982: Edita.

Kreiner, G. E. \& B. E. Ashforth. 2004. Evidence toward an expanded model of organizational identification. Journal of Organizational Behavior, 25(1): 1-27.

Lovas, B. \& S. Ghoshal. 2000. Strategy as guided evolution. Strategic Management Journal, 21(9): 875-96. 
Nooteboom, B., W. Van Haverbeke, G. Duysters, V. Gilsing, \& A. van den Oord. 2007. Optimal cognitive distance and absorptive capacity. Research Policy, 36(7): 1016-34.

Peteraf, M. \& M. Shanley. 1997. Getting to know you: A theory of strategic group identity. Strategic Management Journal, 18: 165-86.

Pettigrew, A. M. 1990. Longitudinal Field Research on Change: Theory and Practice. Organization Science, 1(3): 267-92.

Pratt, M. G. \& P. O. Foreman. 2000. Classifying managerial responses to multiple organizational identities. Academy of Management Review, 25(1): 18-42.

Riketta, M. \& S. Nienaber. 2007. Multiple identities and work motivation: The role of perceived compatibility between nested organizational units. British Journal of Management, 18: S61-S77.

Ruottu, Annina. 1996. Suomalainen tv-näytelmä.In Lemola, T. \& R. Lovio, editors, Miksi Nokia, Finland: WSOY.

Sackmann, S. A. 1992. Culture and Subcultures - an Analysis of Organizational Knowledge. Administrative Science Quarterly, 37(1): 140-61.

Scott, S. G. \& V. R. Lane. 2000. A stakeholder approach to organizational identity. Academy of Management Review, 25(1): 43-62.

Sebestyén, T. 2008. Knowledge Heterogeneity, Alliance Formation and the Evolution of Clusters. Paper presented at 5th International Conference on Innovation and Management, UNU-MERIT, Maastricht.

Sillince, J. A. A. \& A. D. Brown. 2009. Multiple organizational identities and legitimacy: The rhetoric of police websites. Human Relations, 62(12): 1829-56.

Tajfel, H. 1981. Human Groups and Social Categories: Studies in Social Psychology. Cambridge: Cambridge University Press.

Tajfel, H. \& J. Turner. 1979. An Integrative Theory of Intergroup Conflict.In Austin, W. \& Worchel S., editors, The Social Psychology of Intergroup Relations. Monterey, CA: Brooks/Cole.

van de Ven, A. H. \& M. S. Poole. 1995. Explaining Development and Change in Organizations. Academy of Management Review, 20(3): 510-40.

Whetten, D. A. 2006. Albert and Whetten revisited - Strengthening the concept of organizational identity. Journal of Management Inquiry, 15(3): 219-34.

Whetten, D. A. \& P. C. Godfrey, editors. 1998. Identity in Organizations. Building Theory Through Conversations. Thousand Oaks: Sage Publications. 
Willem, A., H. Scarbrough, \& M. Buelens. 2008. Impact of coherent versus multiple identities on knowledge integration. Journal of Information Science, 34(3): 370-86.

Wuyts, S., M. G. Colombo, S. Dutta, \& B. Nooteboom. 2005. Empirical tests of optimal cognitive distance. Journal of Economic Behavior \& Organization, 58(2): 277-302. 


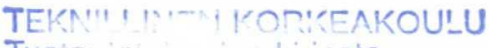

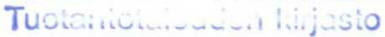

